\title{
Atmospheric Stability Effects on Wind Fields and Scalar Mixing Within and Just Above a Subalpine Forest in Sloping Terrain
}

\author{
Sean P. Burns · Jielun Sun • Donald H. Lenschow • \\ Steven P. Oncley • Britton B. Stephens - Chuixiang Yi • \\ Dean E. Anderson · Jia Hu • Russell K. Monson
}

Received: 13 April 2010 / Accepted: 26 October 2010 / Published online: 20 November 2010

(C) Springer Science+Business Media B.V. 2010

\begin{abstract}
Air temperature $T_{a}$, specific humidity $q, \mathrm{CO}_{2}$ mole fraction $\chi_{c}$, and three-dimensional winds were measured in mountainous terrain from five tall towers within a $1 \mathrm{~km}$ region encompassing a wide range of canopy densities. The measurements were sorted by a bulk Richardson number $R i_{b}$. For stable conditions, we found vertical scalar differences developed over a "transition" region between $0.05<R i_{b}<0.5$. For strongly stable conditions $\left(R i_{b}>1\right)$, the vertical scalar differences reached a maximum and remained fairly constant with increasing stability. The relationships $q$ and $\chi_{c}$ have with $R i_{b}$ are explained by considering their sources and sinks. For winds, the strong momentum absorption in the upper canopy allows the canopy sublayer to be influenced by pressure gradient forces and terrain effects that lead to complex subcanopy flow patterns. At the dense-canopy sites, soil respiration coupled with wind-sheltering resulted in $\mathrm{CO}_{2}$ near the ground being 5-7 $\mu \mathrm{mol} \mathrm{mol}^{-1}$ larger than aloft, even with strong above-canopy winds (near-neutral conditions). We found $R i_{b}$-binning to be a useful tool for evaluating vertical scalar mixing; however, additional information (e.g., pressure gradients, detailed vegetation/topography, etc.) is needed to fully explain the subcanopy wind patterns. Implications of our results for $\mathrm{CO}_{2}$ advection over heterogenous, complex terrain are discussed.
\end{abstract}

Keywords Canopy-layer turbulence - Carbon in the Mountains Experiment (CME04) . Complex terrain $\cdot$ Richardson number $\cdot$ Scalar mixing $\cdot$ Wind fields

S. P. Burns $(\varangle)$ · J. Sun · D. H. Lenschow · S. P. Oncley · B. B. Stephens

National Center for Atmospheric Research, P.O. Box 3000, Boulder, CO 80307-3000, USA

e-mail: sean@ucar.edu

C. $\mathrm{Yi}$

School of Earth and Environmental Sciences, Queens College, Flushing, NY, USA

D. E. Anderson

U.S. Geological Survey, Denver, CO, USA

S. P. Burns · J. Hu · R. K. Monson

Department of Ecology and Evolutionary Biology, University of Colorado, Boulder, CO, USA 


\section{Introduction}

Forests cover approximately $30 \%$ of the land surface on the Earth and have a large impact on the exchanges of energy, water, carbon dioxide, and chemical species between the ground and atmosphere (Raupach 1987; Bonan 2008). These exchanges are often measured using micrometeorological techniques (Baldocchi et al. 1988) that work best for near-neutral, stationary conditions. Interpretation of eddy-covariance measurements during strongly stable conditions is complicated by surface-atmosphere decoupling and horizontal advection (Mahrt 1999; Finnigan 2008). The effect of atmospheric stability on the mixing and exchange of scalars within (and above) a forest has recently been described as an issue that has received "little attention" (Belcher et al. 2008). Early research on canopy-atmosphere exchange focussed on near-neutral conditions over homogeneous, flat terrain and revealed that canopy mixing is primarily achieved by canopy-scale coherent eddies generated at the top of the canopy that lead to "sweeps" and "ejections" of air within the canopy sublayer (CSL, $0 \leq z \leq$ canopy height, $h_{c}$ ) (Kaimal and Finnigan 1994; Finnigan 2000). Because the large vertical shear at the top of the canopy generates the canopy-penetrating eddies similar to those observed in a shear-mixing layer between two coincident flows of differing velocities, this has become known as the "mixing-layer analogy" (Raupach et al. 1996). The scales of these eddies are known to depend on canopy density, and deep within the CSL, von Kármán vortex streets also contribute to the mixing process (Poggi et al. 2004b). Momentum absorption primarily occurs in the upper third of the canopy but depends on the vertical distribution of vegetation density (Raupach and Thom 1981; Brunet et al. 1994; Finnigan and Belcher 2004; Poggi et al. 2004b; Yi 2008). Analytical expressions for how wind and scalars vary throughout the roughness sublayer (RSL, $0 \leq z<2-4 h_{c}$ ) and into the overlying surface layer for flat, horizontal terrain have been determined and include the effect of stability over a limited stability range (Harman and Finnigan 2007, 2008; Siqueira and Katul 2010). For wind, these analytical expressions build on the exponential wind profile formulated by Inoue (1963) coupled with a modified form of the standard Monin-Obukhov similarity functions to smoothly blend the flow between the RSL and the surface layer.

Research on canopy flows has recently shifted from homogeneous flat-ground forests, to situations with the real-world effects of complex terrain, varying stability, forest-gaps and edges (Lee 2000; Staebler and Fitzjarrald 2005; Belcher et al. 2008; Su et al. 2008; Sedlak et al. 2010). As a first step beyond flat-ground canopies, flow over a "forested" hill (i.e., where the streamwise pressure gradient contribution from the hill is no longer negligible in the momentum-balance equation) has been studied using wind-tunnel and flume experiments (Finnigan and Brunet 1995; Poggi and Katul 2007; Poggi et al. 2008), analytically (Finnigan and Belcher 2004), and with large-eddy simulation (LES) modelling (Patton and Katul 2009). In these investigations the flow is near-neutral and the hill of height $H$ is typically shallow (i.e., $H / L_{\text {hill }}$ is small where $L_{\text {hill }}$ is the hill half-width) so that buoyancy does not significantly affect the flow. These studies have shown that, even for a shallow forested hill, the CSL flow responds more quickly than the above-canopy flow to changes in the streamwise pressure gradient. Also, within the CSL, there can be flow separation on the lee side of the hill in the so-called "recirculation region" (Finnigan and Belcher 2004; Poggi and Katul 2007). As stability increases, buoyancy competes with the streamwise pressure gradient to control the flow over the hill; for weakly stable conditions downslope flows are initiated within the canopy near the top of the hill, while the above-canopy flow is relatively unaffected (Belcher et al. 2008). For strongly stable conditions, buoyancy dominates and the flow both above and within the CSL is downslope. For our study, buoyancy is often a primary force driving the flow, however our "hill" is neither shallow nor smoothly-varying and any calculation of 
$L_{\text {hill }}$ is not straightforward. Because these laboratory studies are for flow over simple hills it is unlikely the laboratory results will be directly transferable to a "real-world" flow in complex terrain; they do, however, provide valuable insight into the physical phenomena that can occur.

Our study examines the effect of stability on the three-dimensional wind fields (sonic anemometers) and vertical differences of air temperature $T_{a}$, specific humidity $q$, and $\mathrm{CO}_{2}$ dry air mole fraction $\chi_{c}$ measured during the 2004 Carbon in the Mountains Experiment (CME04, Sun et al. 2010). CME04 took place in a subalpine forest below Niwot Ridge, Colorado, approximately $8 \mathrm{~km}$ east of the Continental Divide (Fig. 1). Air motions over mountains are complicated by abrupt changes in topography, differential heating and cooling of sloped surfaces, orographic lifting, channelling of the flow and the creation of waves and rotors (Smith 1979; Whiteman 2000; Turnipseed et al. 2004; Barry 2008). Most studies related to mountain and slope flows focus on the large-scale (order 10-100 km) aspects of these flows (Smith 1979; Mahrt 1982; Brazel and Brazel 1983; Horst and Doran 1986; Kossmann and Fiedler 2000; Banta et al. 2004; Whiteman and Zhong 2008). Turnipseed et al. (2004) discuss the larger-scale phenomena occurring at the CME04 site and determined that the site is in a region of "shooting flow". Though the site is clearly embedded within a larger-scale mountain-plain wind system, we focus our study on the dynamics of the near-surface winds over an $800-\mathrm{m}$ fetch where the surface drag is highly variable due to changing terrain and canopy structure. The addition of a forest to mountainous terrain leads to further complications such as the interaction between CSL winds and above-canopy synoptic winds that are not aligned with the topography (Feigenwinter et al. 2010), and nocturnal upslope flows that can occur beneath a very dense canopy (Froelich and Schmid 2006). Decoupling of the canopy flow is closely related to the local temperature gradient as described by Froelich and Schmid (2006); their site (with a deciduous closed canopy) experienced upslope sub-canopy flows at night that we did not observe. At our site, the shape of the coniferous trees allows the ground to "view" the sky and cool by direct longwave radiative transfer that generates the downslope, drainage flows near the ground. The relationship between temperature differences and wind gradients above a forested slope have been examined by Komatsu et al. (2005, 2008). Due to the three-dimensional nature of the flow in complex terrain, each individual location can have unique characteristics. A measurement problem that has received much attention related to nocturnal drainage flows is the mean advection of $\mathrm{CO}_{2}$ that occurs below the flux measurement height (Aubinet et al. 2003; Staebler and Fitzjarrald 2004; Leuning et al. 2008; Aubinet 2008; Feigenwinter et al. 2008; Acevedo et al. 2008, and many others). Previous studies at the CME04 site have examined the CSL drainage flows (Yi et al. 2005; Oncley et al. 2009) as well as $\mathrm{CO}_{2}$ advection within the CSL (Sun et al. 2007; Yi et al. 2008). We should note that these advection studies took place in a relatively homogeneous part of the forest within $\approx 200 \mathrm{~m}$ of the AmeriFlux tower on the south side of Como Creek (Fig. 1). One of our objectives is to take a closer look at how the flow patterns change as the flow moves through a heterogenous section of the landscape. The complex terrain at the CME04 site is typical of forested sites that lie within the drainage footprint of a mountain or slope where the topography is generally aligned with the synoptic winds and buoyancy-driven thermotopographic flows are important. Though each site is unique, terrain such as this covers large swaths of land in mountainous regions world-wide; understanding land-atmosphere scalar and momentum exchanges in this situation is important for regional and large-scale weather modelling.

Though it is generally known that convective and near-neutral conditions reduce vertical scalar differences, whilst strongly stable conditions enhance them, it is our goal to quantify the magnitudes of these differences and examine their sensitivity to changes in stability. 


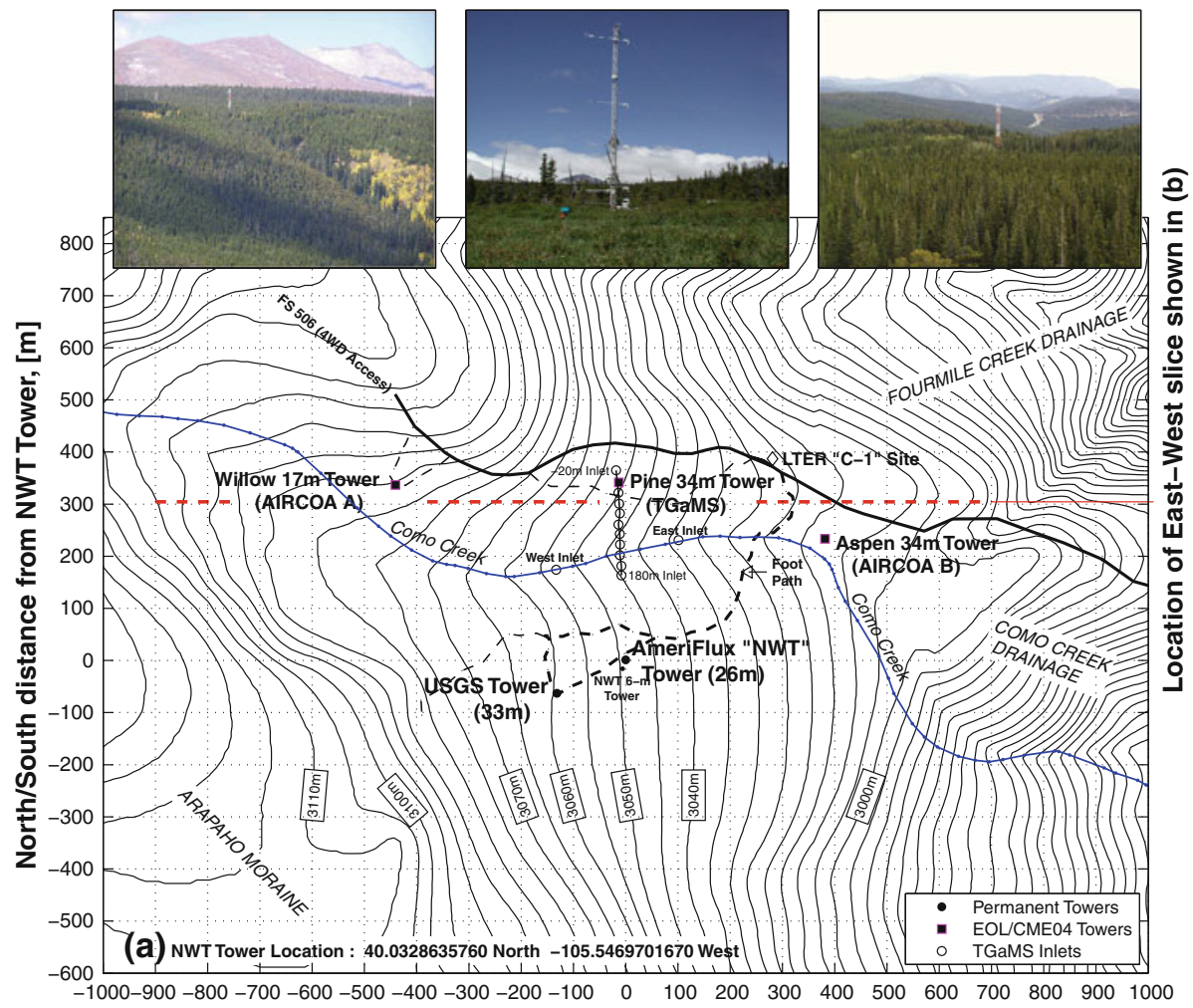

East/West distance from NWT Tower, [m]

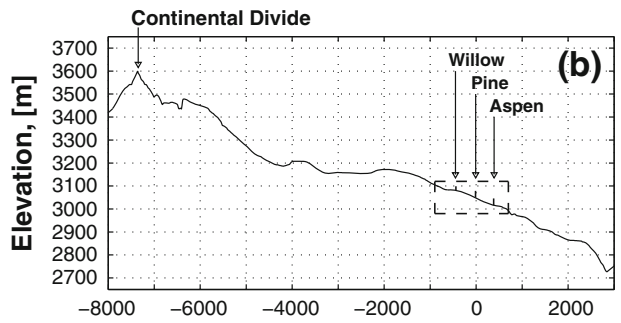

East/West distance from NWT Tower, [m]

Fig. 1 (a) Site topography and the location of the NWT, USGS, Willow, Pine, and Aspen towers used in CME04. The Long-Term Ecological Research (LTER) "C-1" site is a long-term climate station within the Niwot Ridge Biosphere Reserve. Elevation contours at 5-m intervals are from the U.S. Geologic Survey 7.5-min DEM. The photos show (left) NWT, Aspen, and Pine towers (taken from the north-east, looking up the Fourmile Creek drainage), (middle) Willow tower, and (right) Aspen tower (taken from the NWT tower). The horizontal dashed line at $300 \mathrm{~m}$ is the location of the east-west transect shown in (b). In (b) the dashed box represents the area of focus for our study, and the vertical axis has been exaggerated by a factor of five relative to the horizontal axis. The heights of the towers (Willow, Pine, and Aspen) are relative to the vertical scale

In Sect. 2 we consider the equations for conservation of momentum and scalars, and discuss different measures of stability ( $R i$ and $z / \Lambda$ defined later). In Sect. 4.1, we examine how $T_{a}, q, \chi_{c}$, the wind speed $U$, and wind direction $W D$, vary throughout the diurnal cycle for 
an estimate of time-dependent changes in these variables. Section 4.2 compares the bulk Richardson number and $z / \Lambda$, and also looks at how the measured scalars and wind patterns change with stability.

\section{Theoretical Background}

\subsection{Conservation Equations}

If we consider air flowing along a slope of angle $\alpha$ with the coordinate system $x_{1}$ in the along-slope direction and $z_{1}$ normal to the slope (and neglect the Coriolis force, pressure fluctuations, along-slope fluxes, and viscous stress), then the momentum balance is,

$$
\frac{\partial \bar{u}_{1}}{\partial t}+\bar{u}_{1} \frac{\partial \bar{u}_{1}}{\partial x_{1}}+\bar{w}_{1} \frac{\partial \bar{u}_{1}}{\partial z_{1}}=-\frac{1}{\bar{\rho}} \frac{\partial \bar{p}}{\partial x_{1}}+g \frac{\bar{\theta}_{d}}{\bar{\theta}_{o}} \sin \alpha-\frac{1}{\bar{\rho}} \frac{\partial\left(\bar{\rho} \overline{u_{1}^{\prime} w_{1}^{\prime}}\right)}{\partial z_{1}}+F_{D, 1},
$$

where Reynolds averaging has been used to separate the mean from the fluctuations (e.g., $\left.u_{1}=\bar{u}_{1}+u_{1}^{\prime}\right),\left(u_{1}, w_{1}\right)$ are the air velocity components in the $\left(x_{1}, z_{1}\right)$ directions, $\rho$ is air density, $\theta_{o}$ is the potential temperature far from the surface, $\theta_{d}$ is the potential temperature deficit $\left(\theta_{d}=\theta-\theta_{o}\right), p$ is pressure, $\rho \overline{u_{1}^{\prime} w_{1}^{\prime}}$ is the Reynolds shear stress, and $F_{D, 1}$ is the drag on the flow in the $x_{1}$ direction (primarily form drag of the canopy that is negligible above the CSL). Canopy drag is normally parameterised as $F_{D, 1}=c_{d} a \bar{u}^{2}$ where $c_{d}$ is the canopy drag coefficient and $a$ is the foliage area density. Term 4 is the buoyancy term, sometimes called the "hydrostatic pressure gradient". We did not measure the streamwise pressure gradient (term 3), but, for flow over a simple hill, it has been shown to be proportional to the square of the wind speed far above the surface $U_{o}^{2}$ (i.e., $\partial \bar{p} / \partial x_{1} \approx U_{o}^{2} H / L_{\text {hill }}^{2}$ ) (Finnigan and Belcher 2004; Poggi and Katul 2007). Poggi et al. (2008) use a flume experiment to show that linear parameterization of terms 2,3,5, and 6 for near-neutral flow over a shallow hill is reasonable in the upper canopy, but not in the lower canopy where the shear stress is small and advection can be important.

The conservation equation for a scalar with specific concentration $s$ is

$$
\frac{\partial \bar{s}}{\partial t}+\bar{u}_{1} \frac{\partial \bar{s}}{\partial x_{1}}+\bar{w}_{1} \frac{\partial \bar{s}}{\partial z_{1}}=\bar{S}_{s}-\frac{1}{\bar{\rho}} \frac{\partial \bar{\rho}\left(\overline{w_{1}^{\prime} s^{\prime}}\right)}{\partial z_{1}},
$$

where the three terms on the left-hand side represent the time change in $s$ and horizontal and vertical advection. $S_{s}$ is the source or sink of $s$ and $\bar{\rho}\left(\overline{w_{1}^{\prime} s^{\prime}}\right)$ is the flux of $s$ normal to the surface (i.e., in the $z_{1}$ direction). If (1) and (2) are horizontally averaged, then dispersive flux terms due to the large spatial inhomogeneity within the CSL are introduced (Raupach and Thom 1981). Poggi et al. (2004a) have shown that the dispersive fluxes are small within the upper canopy and we neglect them for our study. We also assume that our tower measurements are representative of the local CSL environment. Though advection can be important, scalar profiles are more strongly influenced by the "near-field" sources and sinks within a distance $h_{c}$ of the tower compared to more distant "far-field" influences (e.g., Kaimal and Finnigan 1994, their Sect. 3.3).

For our study we focus on the terms related to the mean scalar concentrations and mean winds in (1) and (2), not the fluxes. In this respect, these equations serve as a guide for our analysis with a goal of observing how stability affects the mean conditions. Furthermore, real world topography does not usually contain perfect slopes as described in (1) and any 
definition of a "slope-following" coordinate system in complex terrain is complicated due to the heterogeneous nature of the topography. For example, the area $2-4 \mathrm{~km}$ to the west of the CME04 tower site is flat (Fig. 1b). Assuming the air passes over that area, it is difficult to know if the flow "resets" or even how to take into account such a region when determining $L_{\text {hill }}, H$, etc. Interpreting the winds and fluxes depends on the coordinate system, and transformations between coordinate systems are common (Finnigan et al. 2003; Finnigan 2004); we use both a Cartesian framework ( $x, y, z$, where the $z$-axis is aligned with gravity and the wind vector $\mathbf{u}=(u, v, w)$ has components in the east-west, north-south, and vertical directions, respectively) as well as a "slope-following" coordinate system $\left(x_{1}, y_{1}, z_{1}\right)$ where the slope angle is estimated by applying a tilt correction to one of the sonic anemometers. We will revisit this topic when we present our results (Sect. 4.2.1).

\subsection{Stability Considerations}

The gradient Richardson number $(R i)$ is the ratio of the relative importance of buoyancy to shear in producing atmospheric turbulence and is a widely-used parameter specifying atmospheric stability (Richardson 1925; Businger 1973; Kaimal and Finnigan 1994). Large negative $R i$ indicates unstable "free convective" conditions and large positive $R i$ indicates strong stability. Historically, it has been assumed that when $R i$ exceeds a certain critical value (typically taken to be $R i_{c} \approx 0.25$ ), the flow is non-turbulent. However, there is evidence that a specific value for $R i_{c}$ does not exist (Galperin et al. 2007; Zilitinkevich et al. 2007). Under strongly stable conditions turbulence continues to occur; however, intermittent wave-related phenomena become the dominant source of turbulence. Another commonly used indicator of stability is $(z-d) / \Lambda$ where $z$ is the height above the ground, $d$ is the zero-plane displacement, and $\Lambda$ is the local Obukhov length $\left(\Lambda=-\left(\left[\left(u_{*}\right)_{z}\right]^{3} \bar{\theta}\right) /\left(\kappa g \overline{w^{\prime} \theta^{\prime}}\right)\right.$ where $\kappa=0.4$ is the von Kármán constant, and $\left(u_{*}\right)_{z}=\left(\left(\overline{u^{\prime} w^{\prime}}\right)_{z}^{2}+\left(\overline{v^{\prime} w^{\prime}}\right)_{z}^{2}\right)^{0.25}$ is the local friction velocity). For our study, we calculate $\Lambda$ and $\left(u_{*}\right)_{z}$ at various heights, each being a local measure and may or may not be representative of the "true" surface value. However, if a well-defined surface layer exists, then $\Lambda$ and $\left(u_{*}\right)_{z}$ are approximately constant within the surface layer and can be used as scaling parameters (e.g., Obukhov length $L$ and friction velocity $u_{*}$ ) in Monin-Obukhov similarity theory (MOST). In strongly stable conditions and within the CSL large flux divergences and phenomena such as canopy-generated waves can invalidate the constant-flux assumptions of MOST, though local scaling may still apply (Nieuwstadt 1984; Mahrt 1999). In this respect $R i$ and $(z-d) / \Lambda$ are quite different; $R i$ is based on the mean differences between measurements heights, whereas $(z-d) / \Lambda$ is a measure of the local turbulence properties. Relationships between $z / L$ and $R i$ are described by Kaimal and Finnigan (1994) and Mauritsen and Svensson (2007), and we revisit this topic again in Sect. 4.2. If the slopes at our site were steeper, then the calculation of $R i$ would need to take into account the slope angle (E. Fedorovich, personal communication, 2010; Fedorovich and Shapiro 2009). Advantages of using $R i$ are that it is calculated from mean values, which makes it suitable for use in atmospheric models (Poulos and Burns 2003). It also avoids the need for fast-response turbulence measurements and the complications of calculating fluxes for intermittent and unsteady flows that can occur under strongly stable conditions or at low wind speeds (Mahrt 1999; Vickers and Mahrt 2006).

Near the ground the bulk Richardson number $\left(R i_{b}\right)$ is often used to characterize stability. To investigate scalar mixing between the CSL and above-canopy air, we calculated $R i_{b}$ between the highest $\left(z_{U} \approx 30 \mathrm{~m}\right.$, at least twice $\left.h_{c}\right)$ and lowest $\left(z_{L} \approx 1 \mathrm{~m}\right)$ measurement levels at each tower using: 


$$
R i_{b}=\frac{g}{\bar{T}_{a}} \frac{\left(\bar{\theta}_{U}-\bar{\theta}_{L}\right)\left(z_{U}-z_{L}\right)}{\bar{U}_{U}{ }^{2}},
$$

where $\bar{T}_{a}$ is average air temperature of the layer, $\bar{\theta}$ is potential temperature, and $\bar{U}$ is the magnitude of the horizontal vectorial mean wind speed (i.e., $\left.\bar{U}=\left(\bar{u}^{2}+\bar{v}^{2}\right)^{1 / 2}\right)$. We did not use $\bar{U}_{L}$ because it refers to a level deep within the CSL where $\bar{U}$ is less than $0.8 \mathrm{~m} \mathrm{~s}^{-1}$, due to the momentum absorbed by the needles, branches and boles of the trees. In this respect, the shear-generated turbulence is related to the above-canopy $U$ whereas the buoyancy is related to the $\theta$ difference between near the ground and the overlying air. Because $R i_{b}$ is a ratio of two variables, it becomes less useful when either the numerator or denominator becomes very small. Depending on the stability, $z_{U}$ may be within the RSL, the surface layer (i.e., where MOST is valid), or, in strongly stable conditions, above the surface layer (Mahrt 1999). For our study, we are investigating the mixing between the CSL and above-canopy air regardless of the layer incorporating $z_{U}$.

\section{Measurements}

\subsection{Site Description}

As part of CME04, the National Center for Atmospheric Research (NCAR) Earth Observing Laboratory (EOL) Integrated Surface Flux Facility (ISFF) group deployed three towers in a subalpine forest to supplement the existing University of Colorado AmeriFlux tower (NWT) and the U.S. Geological Survey (USGS) tower (Oncley 2004; Sun et al. 2010). A detailed description of the long-term NWT measurements $\left(40^{\circ} 1^{\prime} \mathrm{N}, 105^{\circ} 32^{\prime} \mathrm{W}, 3050 \mathrm{~m}\right.$ elevation) can be found in Monson et al. (2002) and Turnipseed et al. (2002, 2003). The tower measurements used herein are from 1 August until 30 September, 2004.

The three EOL towers (hereafter called "Willow", "Pine", and "Aspen") follow the drainage of a small creek (Como Creek) and were located within $800 \mathrm{~m}$ of each other (Fig. 1). In late summer Como Creek ranges anywhere from 1 to $3 \mathrm{~m}$ wide. The geographic features that form the Como Creek drainage are Arapaho Moraine to the south and west, and a slight ridge to the north that separates the hydrologic drainage of Como Creek from Fourmile Creek. Como Creek drains a small area (3-4 $\mathrm{km}^{2}$ ) north-west of the CME04 towers. Though the terrain within $5 \mathrm{~km}$ of the towers can be quite steep, the towers were located in a relatively flat area with a grade ranging from $4-15 \%$. Within $100 \mathrm{~m}$ of each tower, the approximate topographic slope angles are: $4.3^{\circ}$ (NWT), 5.3 (Aspen), 5.5 (Willow), and $6.7^{\circ}$ (Pine).

The forest is around 100 years old, and composed of subalpine fir (Abies lasiocarpa var. bifolia), lodgepole pine (Pinus contorta), Englemann spruce (Picea engelmannii), quaking aspen (Populus tremuloides), and limber pine (Pinus flexilis). The tree density around the NWT tower is around 0.4 trees $\mathrm{m}^{-2}$ with a leaf area index (LAI) of 3.8-4.2 and $h_{c}$ is 12-13 m (Turnipseed et al. 2002). Flux measurements at $21.5 \mathrm{~m}$ on the NWT tower were shown to be within the surface layer (Turnipseed et al. 2003); so most of the highest tower levels are likely above the RSL (though this may depend on atmospheric conditions as we discuss later). The height of maximum vegetation area density depends on the relative number of each tree species at each location (Monson et al. 2010); near the NWT tower the maximum occurs at $z \approx 9 \mathrm{~m}$ (Yi et al. 2005; Moore et al. 2008).

The Willow tower was in an open marshy area $(\approx 200 \mathrm{~m} \times 100 \mathrm{~m})$ dominated by low shrubs $\left(h_{c}<0.5 \mathrm{~m}\right)$, without any tall trees within $50 \mathrm{~m}$ of the tower. The Pine tower was in a fairly dense section of the forest $\left(h_{c} \approx 13 \mathrm{~m}\right)$. The Aspen tower was nearest to Como Creek 
in an area dominated by willows and shrubs that are around 3-4 $\mathrm{m}$ tall interspersed with several larger 10-15 m conifers, and within $30 \mathrm{~m}$ of a stand of aspen trees that grow along Como Creek. The understory at Aspen was more dense than at the other sites, and about $100 \mathrm{~m}$ north-east of Aspen a small clearing leads down into the Fourmile Creek drainage.

\subsection{Tower Instrumentation and Data Details}

Each tower was equipped with multiple levels of sensors and air inlets for measuring $T_{a}, q$, $\chi_{c}, U$, and $W D$ (Sun et al. 2010, plus Tables 1 and 2). In addition to the multi-level measurements, a barometric pressure sensor and radiation sensors were located at each tower. Sap flow was measured in three different tree species within $150 \mathrm{~m}$ of the NWT tower using a heat-pulse method described in Moore et al. (2008). We use the average sap flow from three representative pine trees as an estimate of transpiration at the site.

The temperature and humidity (T/RH) sensors at the EOL and NWT towers were mechanically aspirated and enclosed in a dual-concentric-cylinder shield. Each T/RH sensor on the Willow, Pine, and Aspen towers was calibrated at the ISFF calibration facility and had an estimated field accuracy of about $\pm 0.1^{\circ} \mathrm{C}$ and $\pm 1.5 \%$. Wind speed and direction were primarily measured with sonic anemometers, and most anemometers were mounted on booms pointing in a southerly direction (Table 1) so as to minimise flow distortion due to the tower for the expected wind directions.

Mean $\mathrm{CO}_{2}$ profiles are part of the standard AmeriFlux measurements at the NWT (Monson et al. 2002) and USGS (Yi et al. 2008) towers. Additional $\mathrm{CO}_{2}$ measurement systems added for CME04 were: an Autonomous Inexpensive Robust $\mathrm{CO}_{2}$ analyzer (AIRCOA; Stephens et al. (2006)) at Aspen and Willow towers and the Trace Gas Measurement System (TGaMS; Burns et al. (2009)) at the Pine tower (see Table 2 for the details of each $\mathrm{CO}_{2}$ system). The above-canopy midday $\chi_{c}$ median difference (and standard deviation) between the AIRCOA at Aspen and TGaMS was $0.04 \pm 0.81 \mu \mathrm{mol} \mathrm{mol}^{-1}$ over 2 months (Burns et al. 2009). All the systems used a similar sampling strategy of periodically switching between different inlets and known calibration gases to improve the $\chi_{c}$ measurement accuracy. The transit time of the air between the inlet and the instrument was taken into account in the processing. For consistency, $\chi_{c}$ data from each system were matched to a 5-min time stamp by linear interpolation.

The data-collection software used at the NWT and EOL towers was designed by ISFF and used network time protocol to ensure consistency among the systems. All results for this study are presented in Mountain Standard Time (MST), which is $7 \mathrm{~h}$ behind UTC time. The raw data were recorded at either 1,10 , or $30 \mathrm{~Hz}$; however, for this study, the 5-min statistics (means and variances) are used, which are standard output by the EOL/ISFF software. For simplicity, an overbar will not be shown in subsequent variables and figures. If data from one level for a certain variable were missing for short periods (due to instrument problems) then a linear interpolation (with height) was used to "gap-fill" the missing data. The Aspen data availability (other towers are similar) is: $T_{a}$ and $q>96 \%, \chi_{c} \approx 80 \%$ (due to two multiple-day time gaps), and wind data $\approx 70 \%$. The larger amount of missing wind data was due to rain affecting the sonic transducers. When possible, missing-data statistics are included in the figures.

Both the diurnal cycle (Sect. 4.1) and $R i_{b}$ (Sect. 4.2) analyses use "binned" data, and we use the term "SD-Bin" to indicate the standard deviation of the data within a given bin. For the diurnal cycle analysis, a "bin" contains all the 5-min statistics (e.g., $U, \sigma_{w}^{2}$, etc) collected over 2 months that are within each 30-min time period of the diurnal cycle (e.g., 1200-1230, 1230-1300, etc.). This creates a mix of both sub half-hourly and "day-to-day" information 
Table 1 Details of the temperature, humidity, and wind measurements at each tower during CME04

\begin{tabular}{|c|c|c|c|c|c|c|c|c|c|c|}
\hline \multirow[t]{2}{*}{ Nominal height (m) } & \multicolumn{2}{|l|}{ USGS } & \multicolumn{2}{|l|}{ Aspen } & \multicolumn{2}{|l|}{ Pine } & \multicolumn{2}{|l|}{ Willow } & \multicolumn{2}{|l|}{ NWT } \\
\hline & $\mathrm{T} / \mathrm{RH}^{\mathrm{a}}$ & $\mathrm{U} / \mathrm{WD}^{\mathrm{b}}$ & $\mathrm{T} / \mathrm{RH}^{\mathrm{a}}$ & $\mathrm{U} / \mathrm{WD}^{\mathrm{b}}$ & $\mathrm{T} / \mathrm{RH}^{\mathrm{a}}$ & $\mathrm{U} / \mathrm{WD}^{\mathrm{b}}$ & $\mathrm{T} / \mathrm{RH}^{\mathrm{a}}$ & $\mathrm{U} / \mathrm{WD}^{\mathrm{b}}$ & $\mathrm{T} / \mathrm{RH}^{\mathrm{a}}$ & $\mathrm{U} / \mathrm{WD}^{\mathrm{b}}$ \\
\hline \multirow[t]{3}{*}{30} & 33.0 & 33.0 & 30.54 & 30.54 & 29.69 & 29.69 & & & & \\
\hline & $45 \mathrm{~A}$ & NA & $50 \mathrm{Y}$ & $186.5^{\circ}$ & $50 \mathrm{Y}$ & $163.5^{\circ}$ & & & & \\
\hline & & RMY & & csat & & csat & & & & \\
\hline \multirow[t]{3}{*}{21} & & & & & & & & & 21.5 & 21.5 \\
\hline & & & & & & & & & $35 \mathrm{D}$ & $203^{\circ}$ \\
\hline & & & & & & & & & & csat \\
\hline \multirow[t]{3}{*}{17} & & & & 17.62 & & 16.77 & 16.5 & 17.0 & & \\
\hline & & & & $184.7^{\circ}$ & & $162.2^{\circ}$ & $50 \mathrm{Y}$ & $178.9^{\circ}$ & & \\
\hline & & & & ati & & nuw & & csat & & \\
\hline \multirow[t]{3}{*}{12} & & & & & & & & & & 12.5 \\
\hline & & & & & & & & & & $20^{\circ}$ \\
\hline & & & & & & & & & & ati \\
\hline \multirow[t]{3}{*}{10} & 10.0 & 10.0 & 10.28 & 10.28 & 9.49 & 9.49 & 9.5 & 10.0 & & 9.0 \\
\hline & $45 \mathrm{~A}$ & - & $50 \mathrm{Y}$ & $182.0^{\circ}$ & $50 \mathrm{Y}$ & $160.1^{\circ}$ & $50 \mathrm{Y}$ & $178.1^{\circ}$ & & - \\
\hline & & $425 \mathrm{~A}$ & & ati & & nuw & & ati & & $425 \mathrm{~A}$ \\
\hline \multirow[t]{2}{*}{8} & & & & & & & & & 8.0 & \\
\hline & & & & & & & & & $35 \mathrm{D}$ & \\
\hline \multirow[t]{3}{*}{6} & & 6.0 & 6.43 & 6.43 & 5.82 & 5.82 & 5.5 & 6.0 & & 5.7 \\
\hline & & - & $50 \mathrm{Y}$ & $172.1^{\circ}$ & $50 \mathrm{Y}$ & $161.0^{\circ}$ & $50 \mathrm{Y}$ & $178.3^{\circ}$ & & $190^{\circ}$ \\
\hline & & $425 \mathrm{~A}$ & & gill & & nuw & & ati & & csat \\
\hline \multirow[t]{3}{*}{3} & & 3.0 & & & & & & & & \\
\hline & & - & & & & & & & & \\
\hline & & $425 \mathrm{~A}$ & & & & & & & & \\
\hline \multirow[t]{3}{*}{2} & 2.0 & & 2.26 & 2.26 & 2.22 & 2.22 & 1.5 & 2.0 & 2.0 & 2.56 \\
\hline & 35 & & $50 Y$ & $182.7^{\circ}$ & $50 \mathrm{Y}$ & $159.3^{\circ}$ & $50 \mathrm{Y}$ & $179.9^{\circ}$ & $45 \mathrm{D}$ & $196^{\circ}$ \\
\hline & & & & csat & & csat & & csat & & csat \\
\hline \multirow[t]{3}{*}{1} & & 1.0 & 1.18 & 1.18 & 1.39 & 1.39 & 0.95 & 1.0 & & 1.61 \\
\hline & & - & $50 \mathrm{Y}$ & $182.9^{\circ}$ & $50 \mathrm{Y}$ & $158.4^{\circ}$ & $50 \mathrm{Y}$ & $179.7^{\circ}$ & & - \\
\hline & & $425 \mathrm{~A}$ & & nuw & & nuw & & ati & & $425 \mathrm{~A}$ \\
\hline
\end{tabular}

The height (m), sensor model number, and the angle of the boom (degrees from true north for wind sensors) are provided

a T/RH sensors: "50Y" is the Vaisala 50Y Humitter platinum-resistance (PRT) sensor; "35", "35A", "35D", "45A", and "45D" are the Vaisala HMP25, HMP35A, HMP35D, HMP45A, and HMP45D PRT sensors; sensors on the USGS tower are housed in a naturally aspirated radiation shield (Gill 41000 radiation shield), while sensors on the other towers are mechanically aspirated with either RM Young 43408 aspirated radiation shields (NWT) or a dual-concentric-cylinder shield designed by NCAR/EOL/ISFF

b Wind sensors: "csat" is the Campbell Scientific CSAT-3 3-dimensional sonic anemometer; " $425 \mathrm{~A}$ " is the Vaisala Handar 2-dimensional sonic anemometer; "nuw" is a 3-dimensional sonic designed and built by NCAR EOL/ISSF; "ati" is the Applied Technologies ATI-K 3-dimensional sonic anemometer, "RMY" is the R.M. Young Wind Sentry Set (model 03001) 3-cup anemometer and wind vane, and "gill" is the Gill model R2 3-dimensional sonic anemometer

within the diurnal bins; SD-Bin, however, will primarily reflect the "day-to-day" variability, so we use the term "variability" when discussing it. For $R i_{b}$, a "bin" is defined as a selected range of $R i_{b}$. 
Table 2 Details of the $\mathrm{CO}_{2}$ measurements at each tower during CME04

\begin{tabular}{|c|c|c|c|c|c|}
\hline & USGS & Aspen & Pine & Willow & NWT \\
\hline System & & AIRCOA" "B" & $\mathrm{TGaMS}^{\mathrm{b}}$ & AIRCOA a "A" & \\
\hline Levels (m) & $\begin{array}{l}1,3,6 \\
10,33\end{array}$ & $\begin{array}{l}1,2,6 \\
10,17,30\end{array}$ & $\begin{array}{l}1,2,6 \\
10,17,30\end{array}$ & $\begin{array}{l}0.5,1,2 \\
6,10,17\end{array}$ & $\begin{array}{l}0.5,1,2, \\
5,10,21.5\end{array}$ \\
\hline $\mathrm{CO}_{2}$ sensor $^{\mathrm{c}}$ & LI-7000 & LI-820 & LI-7000 & LI-820 & LI-6251 \\
\hline $\begin{array}{l}\text { Sample } \\
\text { Resolution }{ }^{\mathrm{d}} \text { (min) }\end{array}$ & 30 & 15 & 30 & 15 & 6 \\
\hline Air drying method & None & Nafion & Nafion & Nafion & $\begin{array}{l}\text { Magnesium } \\
\text { perchlorate }\end{array}$ \\
\hline $\begin{array}{l}\text { Calibration } \\
\text { Gases }^{\mathrm{e}} \\
\qquad\left(\mu \mathrm{mol} \mathrm{mol}^{-1}\right)\end{array}$ & $\begin{array}{l}0 \text { and } 414.3 \\
(0 \text { and } 412.3)\end{array}$ & $\begin{array}{l}342.10,370.41 \\
405.35,471.23\end{array}$ & $\begin{array}{l}334.88,349.27 \\
398.14,417.95\end{array}$ & $\begin{array}{l}344.11,366.53 \\
401.75,474.64\end{array}$ & 0 and 401.33 \\
\hline $\begin{array}{l}\text { Calibration } \\
\text { Frequency }^{\mathrm{f}}(\mathrm{hr})\end{array}$ & 2 (full) & $\begin{array}{l}3.5 \text { (full) } \\
0.5 \text { (partial) }\end{array}$ & $\begin{array}{l}2.5 \text { (full) } \\
0.5 \text { (partial) }\end{array}$ & $\begin{array}{l}3.5 \text { (full) } \\
0.5 \text { (partial) }\end{array}$ & 4 (full) \\
\hline
\end{tabular}

The 1-m inlet at NWT and the 1-m inlet at Willow were not used

a AIRCOA: "Autonomous Inexpensive Robust CO2 Analyzer" (Stephens et al. 2006)

b TGaMS/HYDRA: designed by Tony Delany at NCAR EOL/ISFF (Burns et al. 2009)

c All $\mathrm{CO}_{2}$ closed-path sensors are manufactured by LI-COR Biosciences Inc. (4308 Progressive Ave. Lincoln, Nebraska USA). The model number of the sensor used is shown in the table

d Sample resolution: the frequency at which any single inlet is sampled

e The calibration gases used at Pine, Willow, Aspen, and NWT were pre- and post-calibrated at the NCAR $\mathrm{O}_{2} / \mathrm{CO}_{2}$ Calibration Facility (http://www.eol.ucar.edu/ stephens/CALFAC) and are reproducible to $\pm 0.05 \mu \mathrm{mol} \mathrm{mol}^{-1}$ with an estimated uncertainty of $\pm 0.1 \mu \mathrm{mol} \mathrm{mol}^{-1}$ relative to the World Meteorological Organization (WMO) $\mathrm{CO}_{2}$ Mole Fraction Scale. The USGS calibration gases were prepared in a USGS laboratory using a NOAA Global Monitoring Division (GMD) standard cylinder and a LI-COR LI-6262 IRGA f The time (hr) between calibrations. A "full" calibration uses all available calibration gases, while a "partial" calibration uses only one of the calibration gases

\section{Results and Discussion}

The diurnal patterns measured at the Aspen tower are presented below. Though the other CME04 towers show similar patterns, there are also important differences related to the canopy structure near each tower. A quantitative comparison of the canopy structure at each tower is beyond the scope of the current study, though we will, however, qualitatively highlight the effect of different canopy structures on the measurements. Note that the mean diurnal patterns shown here are affected by a wide variety of atmospheric phenomena (e.g., gravity wave breaking, inconsistent and variable fetch, clouds) and we recognise that it is not possible to discern the effects of all these phenomena from our analysis. Following the diurnal patterns, the data binned by $R i_{b}$ are presented; understanding the daily cycle creates the context for the $R i_{b}$ analysis.

\subsection{Diurnal Pattern (Aspen Tower)}

Late-summer scalar concentrations and wind patterns at the site are revealed by the composited diurnal cycles of $T_{a}, q$, and $\chi_{c}$ (Fig. 2) and $U$ and $W D$ (Fig. 3). For our high-elevation site, the above-canopy average net radiation $R_{n e t}$ is $500 \mathrm{~W} \mathrm{~m}^{-2}$ at midday and $-50 \mathrm{~W} \mathrm{~m}^{-2}$ at night (Fig. 2a). Solar heating causes daytime $T_{a}$ near the ground to be $\approx 10^{\circ} \mathrm{C}$ greater than nighttime $T_{a}$ (Fig. 2a), and this warmer layer of air helps form a convective boundary layer 
[D०] "n $L$ u!g-CS

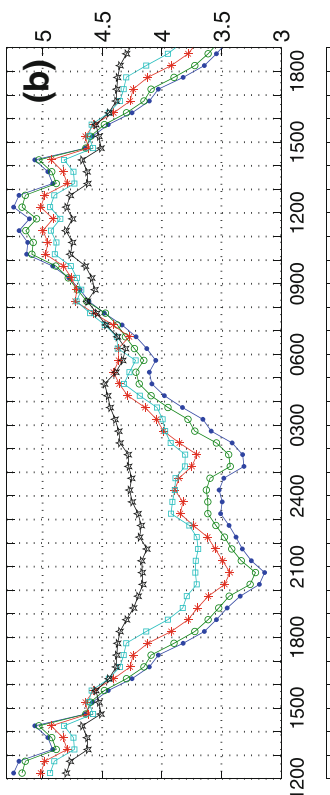

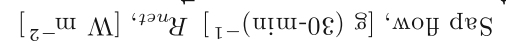

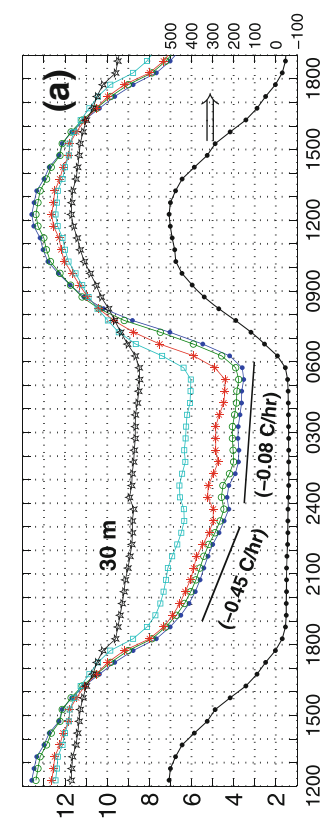

$\left[\mathrm{D}_{\circ}\right]{ }^{\prime n} L$

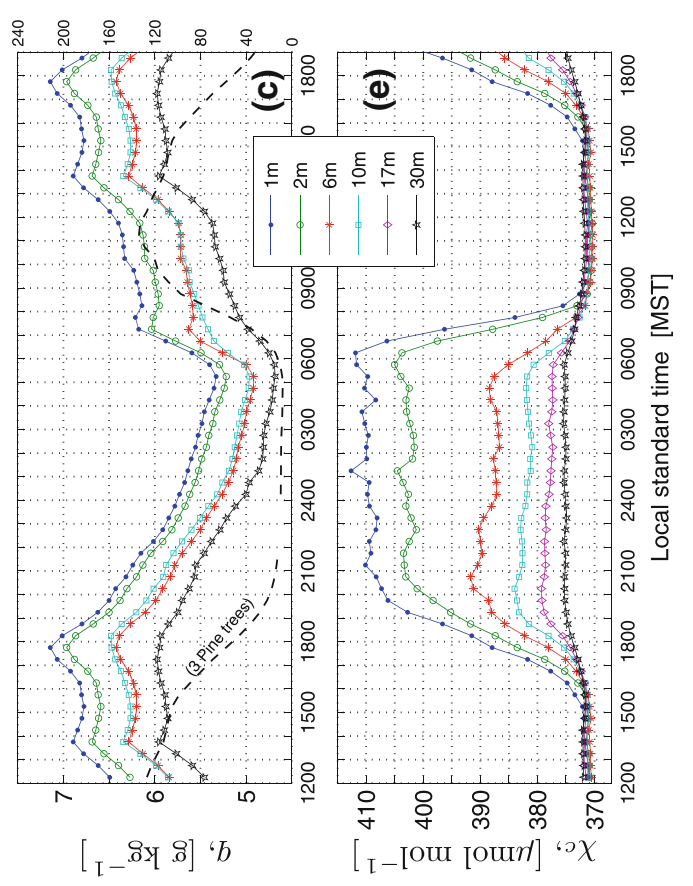

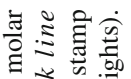
Oे

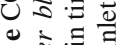

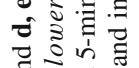

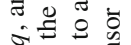

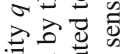

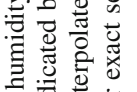

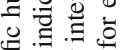
氜 范苾 च远 -

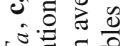
昰言

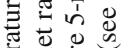
푼

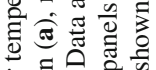

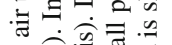
음.

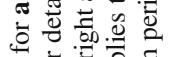
훙 量产 गे इ ब

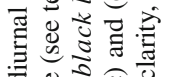
寻造过 卷芯可

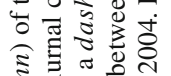

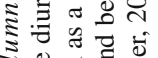
ชㄹ

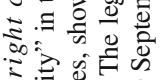
ఏ) ติ่ की

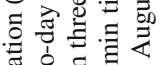
. ఫ 는 言节灾战 क ส

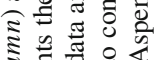
वे 0 0 웅

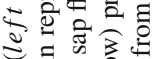
10

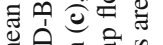

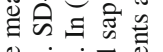
E $\dot{\dot{x}} \dot{\vec{n}} \vec{\Xi}$ ‥

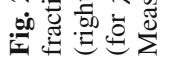



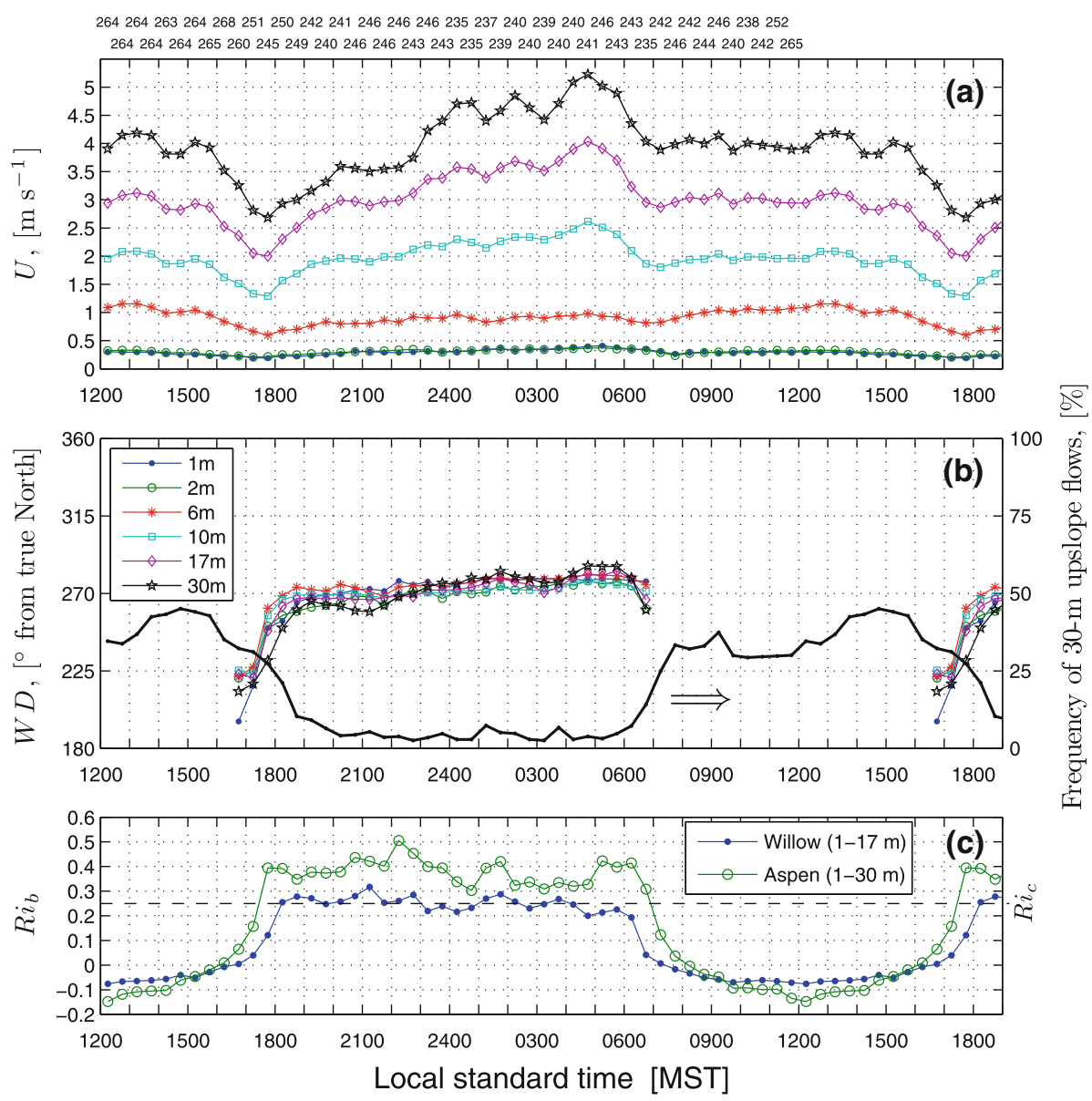

Fig. 3 The mean diurnal cycle for a wind speed $U$, b wind direction $W D$, and $\mathbf{c}$ bulk Richardson number $R i_{b}$. The number of 5-min data within each 30-min bin are shown above (a), where a value of 366 means no missing data. In (b), the percentage of time upslope winds $\left(35^{\circ}<W D<145^{\circ}\right)$ occurred is given by the thick black line (right axis) and daytime $W D$ is not shown because the above-canopy $W D$ during the daytime had a bi-modal frequency distribution (see text for further details). The legend in (b) also applies to (a). See the caption of Fig. 2 for additional details

with enhanced vertical mixing as indicated by the relatively large daytime values of vertical velocity variance $\sigma_{w}^{2}$ (Fig. $4 \mathrm{c}$ ). At night, $\sigma_{w}^{2}$ is largest just above the top of the CSL $(10 \mathrm{~m})$ due to increased turbulence from the canopy elements.

The SD-Bins (i.e., "day-to-day" variability) of selected variables are shown in Fig. 2 (scalars) and Fig. 4 (vertical wind). The variability of $T_{a}$ and $q$ is greatest during the day due to a wide range of daytime solar radiation (e.g, clear days versus cloudy days), as well as a mixture of upslope and downslope flows. During the night, the variability of $T_{a}$ is much larger at $30 \mathrm{~m}$ than near the ground due to the consistent "drainage-flow" conditions near the ground, while the above-canopy air is subject to a variety of synoptic conditions (Fig. 2b). Just before midnight, turbulent mixing events are more frequent (Fig. 4d), which increases the variability of near-ground $T_{a}$ and is one reason that the near-ground cooling rate decreases from 0.45 to $0.08^{\circ} \mathrm{C} \mathrm{h}^{-1}$ (Fig. 2a). 


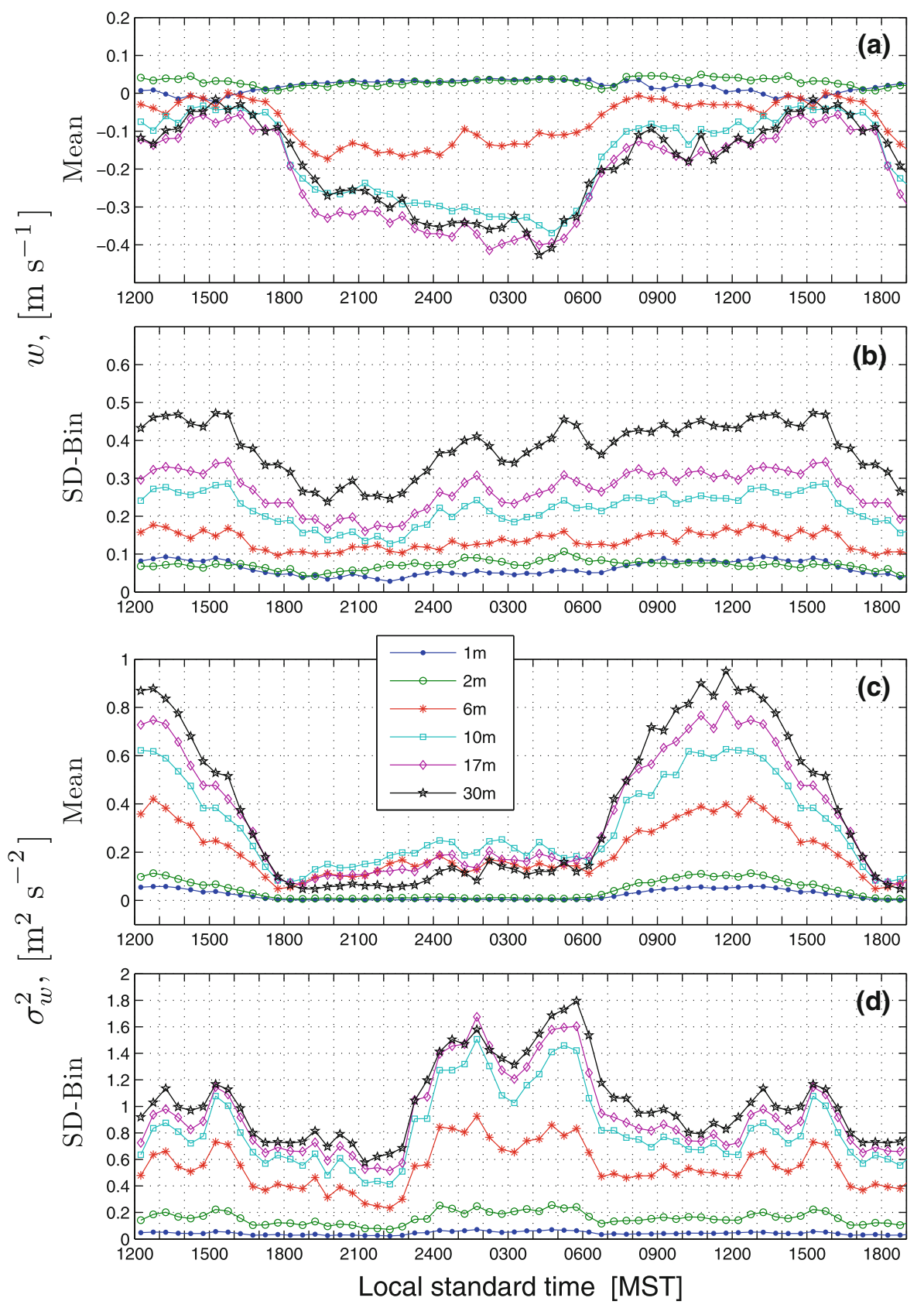

Fig. 4 The mean and standard deviation (SD-Bin) of the diurnal cycle at the Aspen tower for a, b vertical wind in gravity-based coordinates $w$, and $\mathbf{c}, \mathbf{d} 5$-min $w$ variance $\sigma_{w}^{2}$. The legend in (c) applies to all panels. See the caption of Fig. 2 for additional details

The specific humidity gradually decreases throughout the night (Fig. 2c) primarily due to: (1) the closure of plant stomata effectively cutting off transpiration, and (2) the advection of drier air from higher elevations past the tower site. Vertical mixing and entrainment of drier 
air from aloft, and any condensation or dew formation (fairly uncommon at the site), further dry the atmosphere. The peak in humidity at sunset (1700-1800 MST) occurs when $U$ and $\sigma_{w}^{2}$ are both at a minimum and the trees are still transpiring, as shown by the dashed line in Fig. 2c. The transpiration, combined with inhibited vertical mixing, effectively traps water vapour near the surface causing the humidity to increase simultaneously at all tower levels. Early in the morning (between 0630-0730 MST) there is a marked increase in humidity at all the levels below $6 \mathrm{~m}$, which coincides with the start of early-morning transpiration by the vegetation as well as the morning transition to upslope winds (if they occur). Strong vertical mixing of the atmosphere by 0800 MST makes any daytime transpiration effects less obvious.

The relatively well-mixed $\mathrm{CO}_{2}$ during the daytime (due to convection) and the nighttime increase of $\mathrm{CO}_{2}$ near the ground are caused by a combination of biological and meteorological factors (Bakwin et al. 1995; Yi et al. 2001; Schaeffer et al. 2008; Pérez et al. 2009). At night, the primary sink of $\mathrm{CO}_{2}$ (uptake by photosynthesis) ceases, but the heterotrophic respiration by soil microbes and autotrophic respiration by roots (i.e., $\mathrm{CO}_{2}$ sources) continue. Starting about $1600 \mathrm{MST}$, as vertical mixing decreases, the near-ground $\chi_{c}$ gradually increases until, by $2100 \mathrm{MST}$, quasi steady-state conditions are achieved and $\chi_{c}$ at all heights above the ground becomes fairly constant with time (Fig. 2e). It is important to note the timing of the $\chi_{c}$ increase at each level; $\chi_{c}$ at the 1-m level starts to increase at about $1600 \mathrm{MST}$, followed by the $2-\mathrm{m}$ level an hour later, etc. The increase of $\chi_{c}$ starting at the lowest levels indicates the turbulent and diffusive transfer of ground-level $\mathrm{CO}_{2}$ upward to higher levels. This sequential pattern of $\chi_{c}$ increase can be contrasted with humidity $q$, which simultaneously increases at all levels because water vapour is transpired throughout the canopy (along with some evaporation at the ground).

The variability of $\chi_{c}$ is at a minimum during the day due to enhanced atmospheric mixing and photosynthetic uptake of $\mathrm{CO}_{2}$ (Fig. 2f). Variability of $\chi_{c}$ near the ground is greater at night because there are either strong winds that mix the $\mathrm{CO}_{2}$ to higher levels of the atmosphere, or stable conditions that inhibit mixing. There can also be $\chi_{c}$ variations due to changes in the soil temperature that affects the generation of $\mathrm{CO}_{2}$ by microbes (Hirano et al. 2003; Scott-Denton et al. 2003; Ryan and Law 2005). The variability of the 30-m $\chi_{c}$ is fairly constant throughout the diurnal cycle, indicating that the $30-\mathrm{m}$ level is high enough to be isolated from most of the surface-related diurnal processes.

Characteristic of sloping terrain with a heated or cooled surface, the site often experiences upslope or downslope winds depending on the balance between the hydrodynamic (term 3) and hydrostatic (term 4) pressure-gradient forces in Eq. 1 (Sutton 1953; Mahrt 1982; Monti et al. 2002; Froelich and Schmid 2006). The daytime diurnal pattern for WD is not shown in Fig. $3 b$ because the flow can be either upslope or downslope, which creates a bi-modal frequency distribution such that the mean or median value is meaningless (Fig. 5b). Within the canopy during daytime, almost any wind direction is possible. In general, night-time flows at all levels were downslope (Figs. 3b, 5d), though there were some interesting flow dynamics that will be discussed when we consider $W D$ binned by $R i_{b}$ (Sect. 4.2.1). The above-canopy day and night $U$ frequency distributions are somewhat skewed due to a significant number of times that the $30-\mathrm{m}$ level $U>9 \mathrm{~m} \mathrm{~s}^{-1}$, as seen by the difference between the mean and median in Fig. 5a and c.

The gradual increase of $U$ throughout the night (Fig. 3a) is typical of air flow under stable conditions, and indicative of the atmosphere decoupling from the surface (Sutton 1953; Businger 1973; Mahrt 1999). A significant feature in the diurnal wind pattern is that between 2200-2400 MST there is a sudden increase in the variability of $\sigma_{w}^{2}$ (Fig. 4d). This feature is likely related to $U$ increasing to the point where shear-generated turbulence is reinitiated. 
(a)

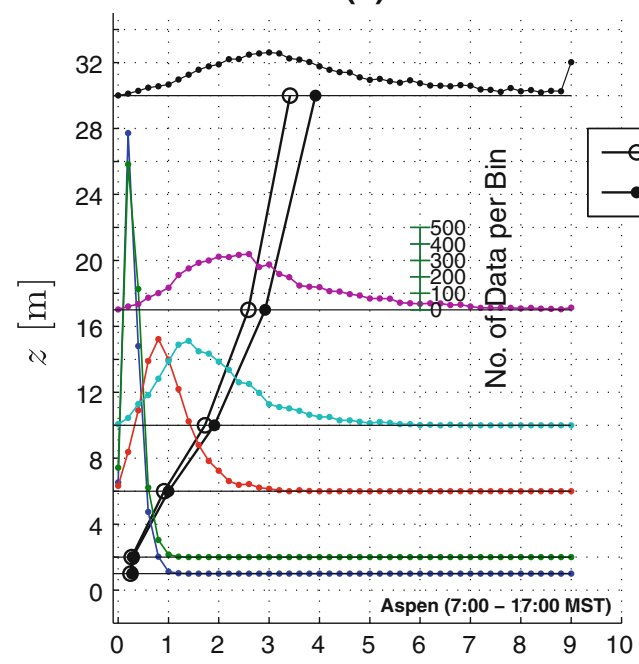

(c)

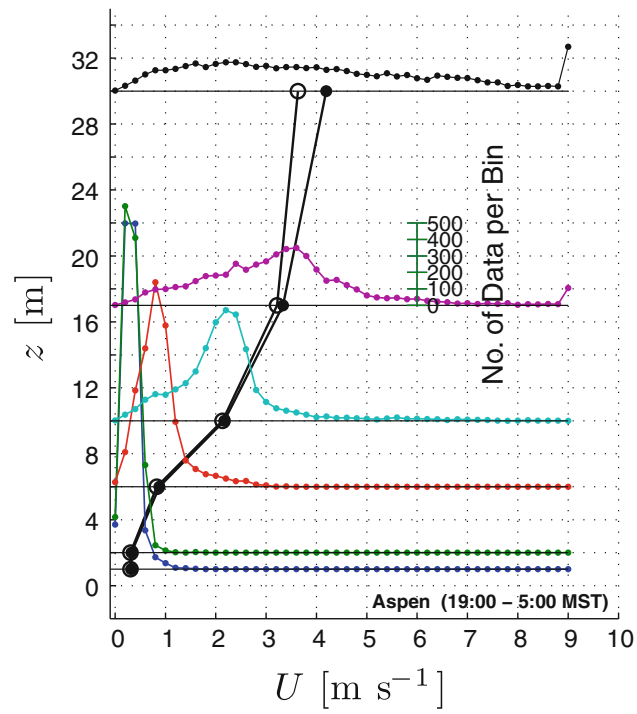

(b)

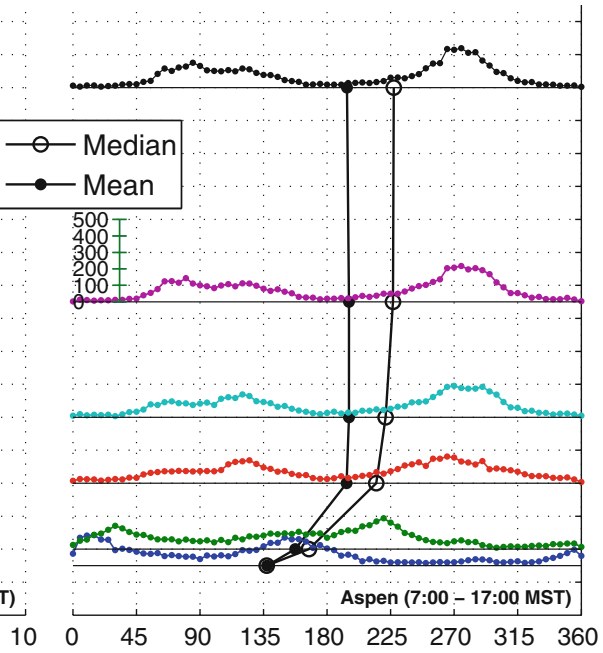

(d)

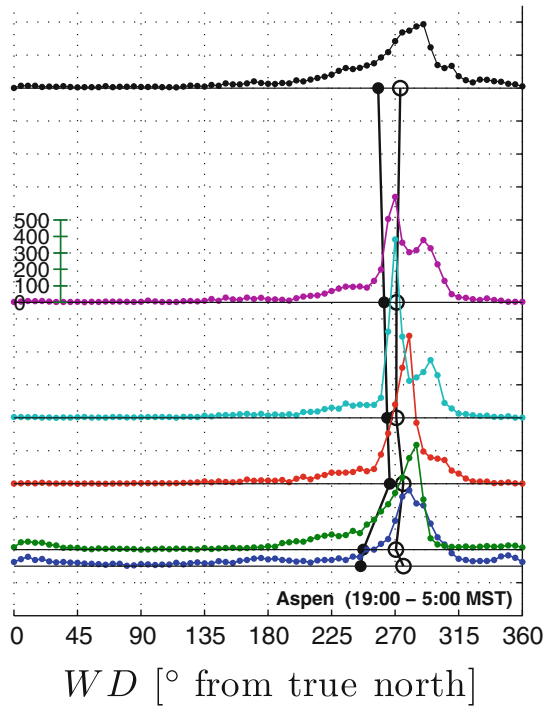

Fig. 5 Frequency distributions of daytime a wind speed $U$, and $\mathbf{b}$ wind direction $W D$, and nighttime $\mathbf{c} U$ and d $W D$ for different levels on the Aspen tower. For $U$, the number of values $9 \mathrm{~m} \mathrm{~s}^{-1}$ or greater are shown in the final $U$ bin. Data used are 5-min averages

This aspect of the flow dynamics will not be explored further here, but has implications on the timing of nocturnal mixing as discussed previously.

\subsection{Binning of Tower Data by $R i_{b}$}

Figure 6 shows $R i_{b}$ compared with $(z-d) / \Lambda$ along with the empirical relationship between $R i$ and $z / L$ as described in Kaimal and Finnigan (1994), viz: $R i=z / L$ for $(-2 \leq R i \leq 0)$, 

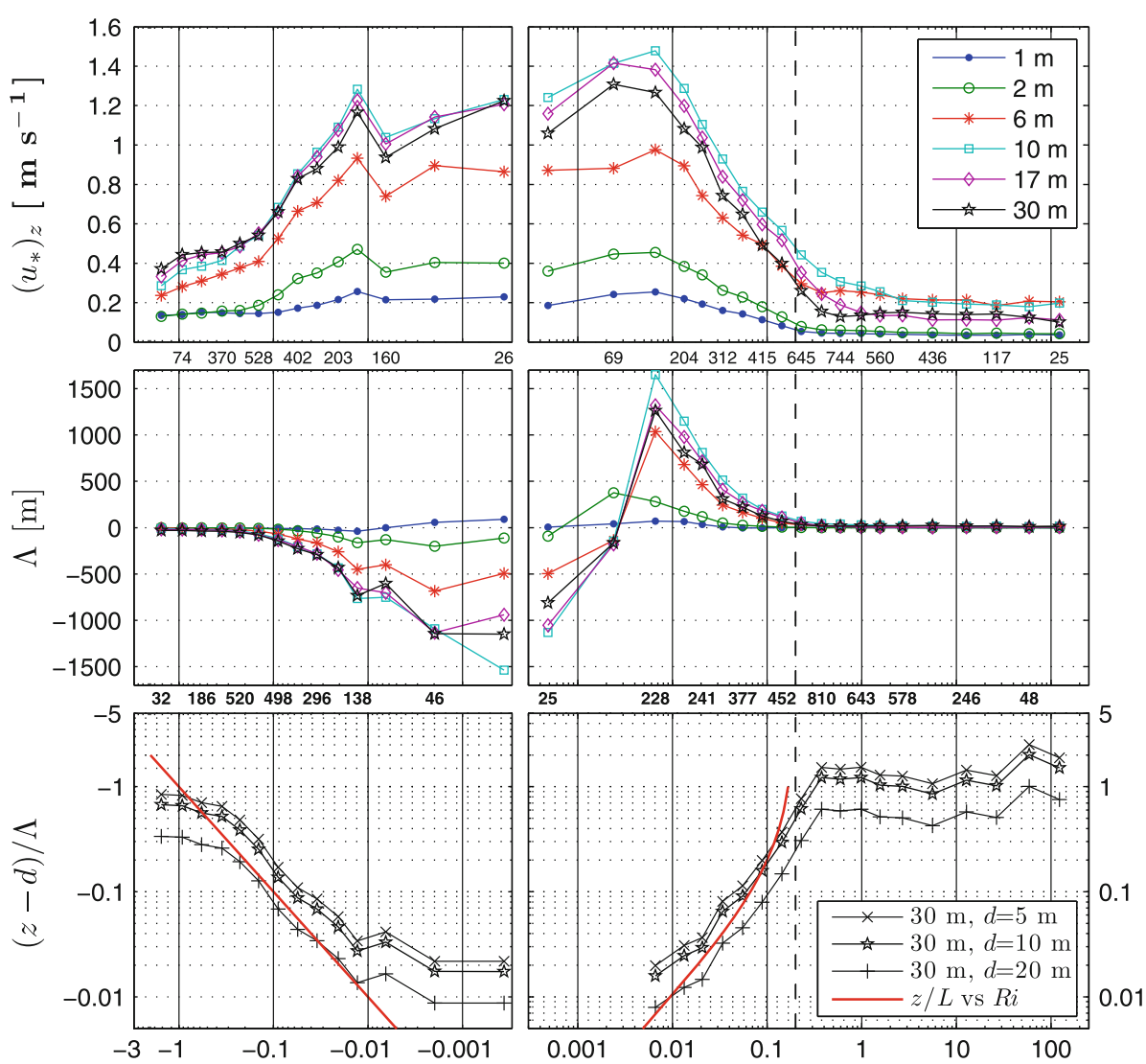

$R i_{b}$

Fig. 6 The local friction velocity $\left(u_{*}\right)_{z}=\left(\left(\overline{u^{\prime} w^{\prime}}\right)_{z}^{2}+\left(\overline{v^{\prime} w^{\prime}}\right)_{z}^{2}\right)^{0.25}$, local Obukhov length $\Lambda$, and $(z-d) / \Lambda$ at 30-m (for three different zero-plane displacements $d$ ) binned by the bulk Richardson number at the Aspen tower. Note that the left and right panels for $(z-d) / \Lambda$ have different $y$-limits and negative $(z-d) / \Lambda$ values are not shown in the right panel; the red curve is the empirical expression between $R i$ and $z / L$ as described in Kaimal and Finnigan (1994) (see text for details). The vertical dashed line at $R i_{b}=0.25$ has historically been considered the "critical value" for turbulence. The number of 5-min data within each bin are shown above/below the $\Lambda$ panel

and $R i=(z / L)(1+5 z / L)^{-1}$ for $(0 \leq R i \leq 1 / 6)$. Because these $R i$ vs $z / L$ relationships are only valid within the surface layer, regions where $R i$ compares well with $R i_{b}$ are probably when the 30-m level lies within the surface layer. Different values of $d$ are shown to indicate the sensitivity of the relationships to changes in $d$. Harman and Finnigan (2007) show that $d$ is not a true constant, but depends on the flow conditions. When shear-generated turbulence is suppressed both $\left(u_{*}\right)_{z}$ and $\Lambda$ become small (and nearly constant). The difference between using $R i_{b}$ or $(z-d) / \Lambda$ as a "stability parameter" is most evident for strongly stable conditions $\left(R i_{b}>1\right)$ where $(z-d) / \Lambda$ becomes nearly constant and $R i_{b}$ varies by two orders of magnitude; in these conditions, the 30-m level is decoupled from the surface and MOST surface-layer scaling is not appropriate. For near-neutral and strongly unstable conditions the $(z-d) / \Lambda$ data do not follow the empirical relationship very closely. This is likely due to the 30-m level being within the RSL rather than the surface layer, since the RSL becomes 
deeper in these conditions (Physick and Garratt 1995; Nakamura and Mahrt 2001) (also $R i_{b}$ is only an approximate measure of $R i$ ).

We first focus on the effect of stability on the winds, and then discuss the scalars $\left(T_{a}, q, \chi_{c}\right)$ under unstable $\left(R i_{b}<0\right)$ and stable $\left(R i_{b}>0\right)$ conditions.

\subsubsection{Winds}

In gravity-based coordinates, upper-level winds at Aspen show a clear downward movement of air at night, but the 1-m and 2-m levels have positive $w$ (Figs. 4a and 7b). This indicates flow convergence in the middle and upper parts of the canopy. Because the sonic anemometers were oriented with gravity there is a component of the horizontal "slope-following" wind in $w$ (Sun 2007). The planar-fit method (Wilczak et al. 2001) re-orients the coordinate system so that the mean of $w_{1}$ is zero over the time period used to determine the mean streamline (typically weeks or months). This allows the mean $w_{1}$ to be non-zero over shorter time periods, such as the half-hour periods that are often used to calculate fluxes. For our analysis, we have assumed that the planar-fit coordinate system is equivalent to the slope-coordinate system $\left(x_{1}, y_{1}, z_{1}\right)$. Wilczak et al. (2001) discuss the various advantages and disadvantages of using the planar-fit method and note that there can be residual effects of stability on $w_{1}$ over sloping terrain. If strong convergence and divergence causes the streamlines to change significantly between each stability regime, there may be some distortion when the planar-fit is applied to all the data. To investigate this further, we plotted $w_{1}$ versus $R i_{b}$ where the planar-fit coefficients are determined from the upper-level sonic and then applied to each lower-level sonic (Fig. 7c). To apply the coefficients in this way, it is crucial that all the sonics be carefully aligned with gravity. If the mean streamline is invariant to stability changes, then $w_{1} \approx 0$ for all $R i_{b}$. We find that $w_{1}$ changes with stability; and, more importantly, the streamlines at the sites with trees show the strongest divergences and convergences for flow in windy, near-neutral conditions. Though this is an important issue (e.g.,Mahrt 2010), it is somewhat peripheral to our current study, which focuses on the scalars; however, we note that the mean subcanopy flow at Aspen is most strongly directed away from the surface (e.g., $w>0, w_{1}>0$ ) for near-neutral conditions.

To gain further insight into the flow under different stability conditions, we divided the measurements into five stability classes by selecting $R i_{b}$ ranges where changes in $w$ are relatively small (see Fig. $7 \mathrm{~b}$ for the various classes). After creating these classes, the mean wind vectors from each tower are plotted in the horizontal $(x-y)$ plane along with corresponding $U$ profiles and $W D$ frequency distributions (Fig. 8). What emerges is a clearer picture of how the flow at the site changes with stability. At the Aspen tower, vertical differences in $U$ and $W D$ binned by stability (i.e., $R i_{b}$ ) and the corresponding SD-Bins are shown in Figs. 9 and 10 , respectively.

As mentioned previously, when conditions are strongly unstable, the daytime wind patterns are complex because either upslope or downslope flows can be present (Fig. 5b). For this reason we separated the unstable data into upslope and downslope conditions based on the 30-m wind direction at Aspen (Figs. 8a-b, and 11). For unstable upslope flows, wind speeds are low and rarely greater than $4 \mathrm{~m} \mathrm{~s}^{-1}$; furthermore, the upper- and lowerlevel winds are generally aligned with each other, and the near-ground wind directions at Aspen appear to be coming from either the Fourmile or Como Creek drainage (note that the two peaks in the WD frequency distribution of Fig. $8 \mathrm{a} 2$ are closely aligned with the direction to the drainages). In contrast, when the upper-level (synoptic) winds are downslope, the low-level winds at Willow are downslope, but the Aspen and Pine CSL winds are both upslope and the CSL WD at Aspen is (again) strongly influenced by the two creek 

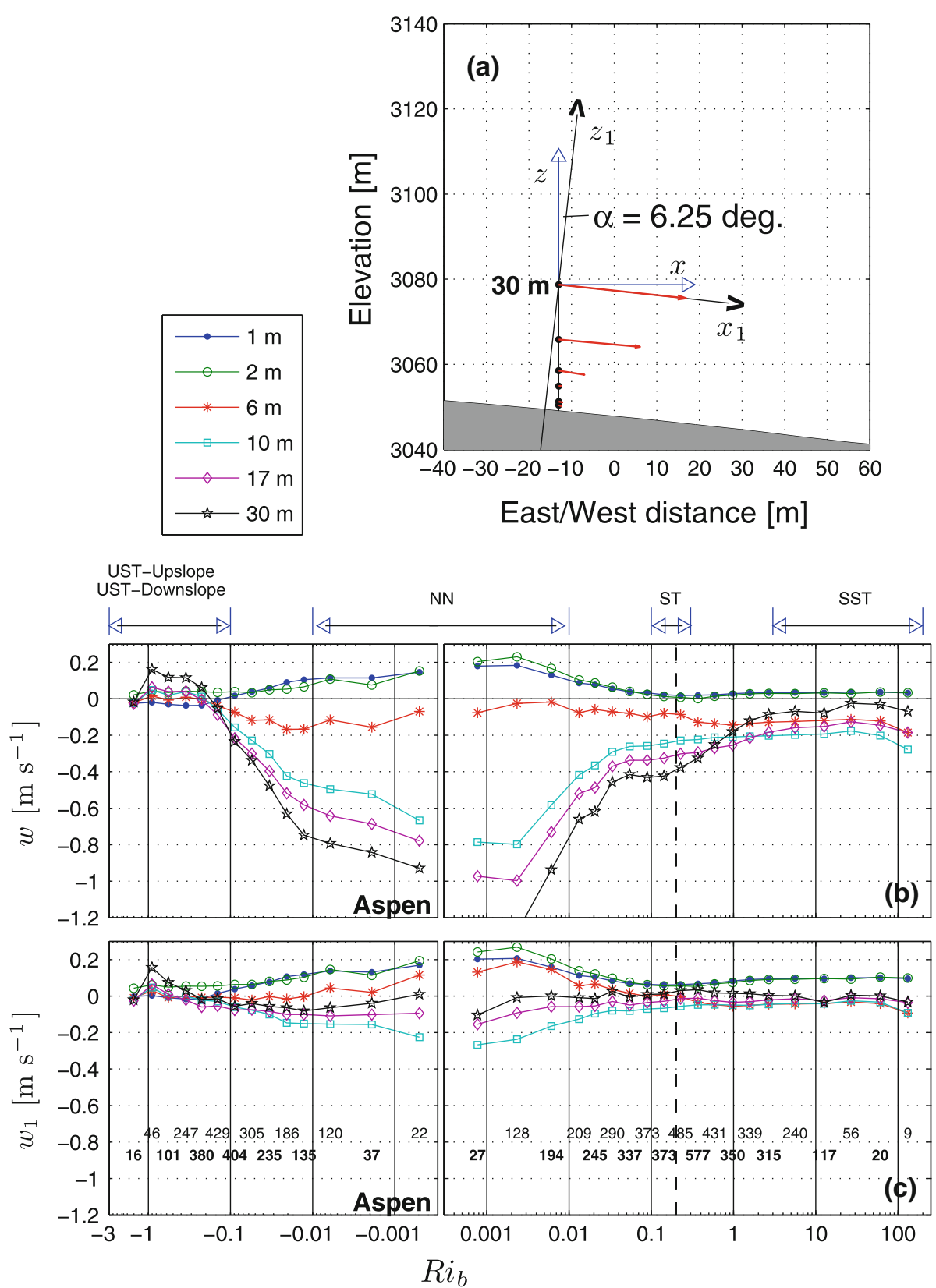

Fig. 7 a Gravity-based $(x, y, z)$ and slope-based $\left(x_{1}, y_{1}, z_{1}\right)$ coordinate systems at the Pine tower. For each level, the wind vector is shown as a red arrow and the slope angle $\alpha$ is determined using the planar-fit method with the 30-m wind data (note, this is not a "schematic" these wind vectors are for $\left|R i_{b}\right|<0.01$ ). Lower panels: vertical wind component in $\mathbf{b}$ gravity-based $w$ and $\mathbf{c}$ planar fit-based $w_{1}$ coordinates binned by $R i_{b}$ for the Aspen tower. The number of points within each bin are shown in (c). The planar-fit coefficients are determined using the 30-m sonic anemometer and then applied to the lower levels. The vertical lines above (b) designate the $5 R i_{b}$ ranges selected for analysis which are: UST (unstable) upslope and downslope, NN (near-neutral), ST (stable), and SST (strongly stable) as described in the text 


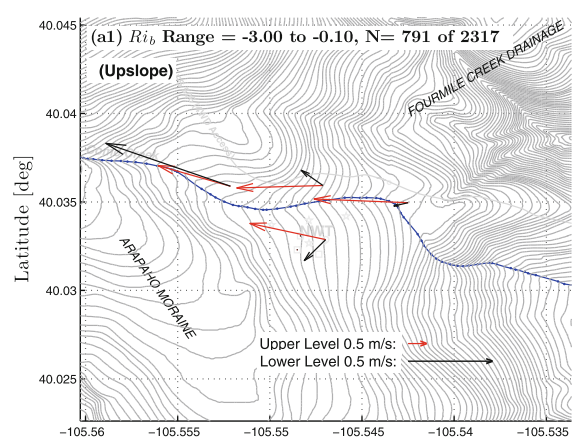

(a2) $R i_{b}$ Range $=-3.00$ to -0.10 (Upslope)
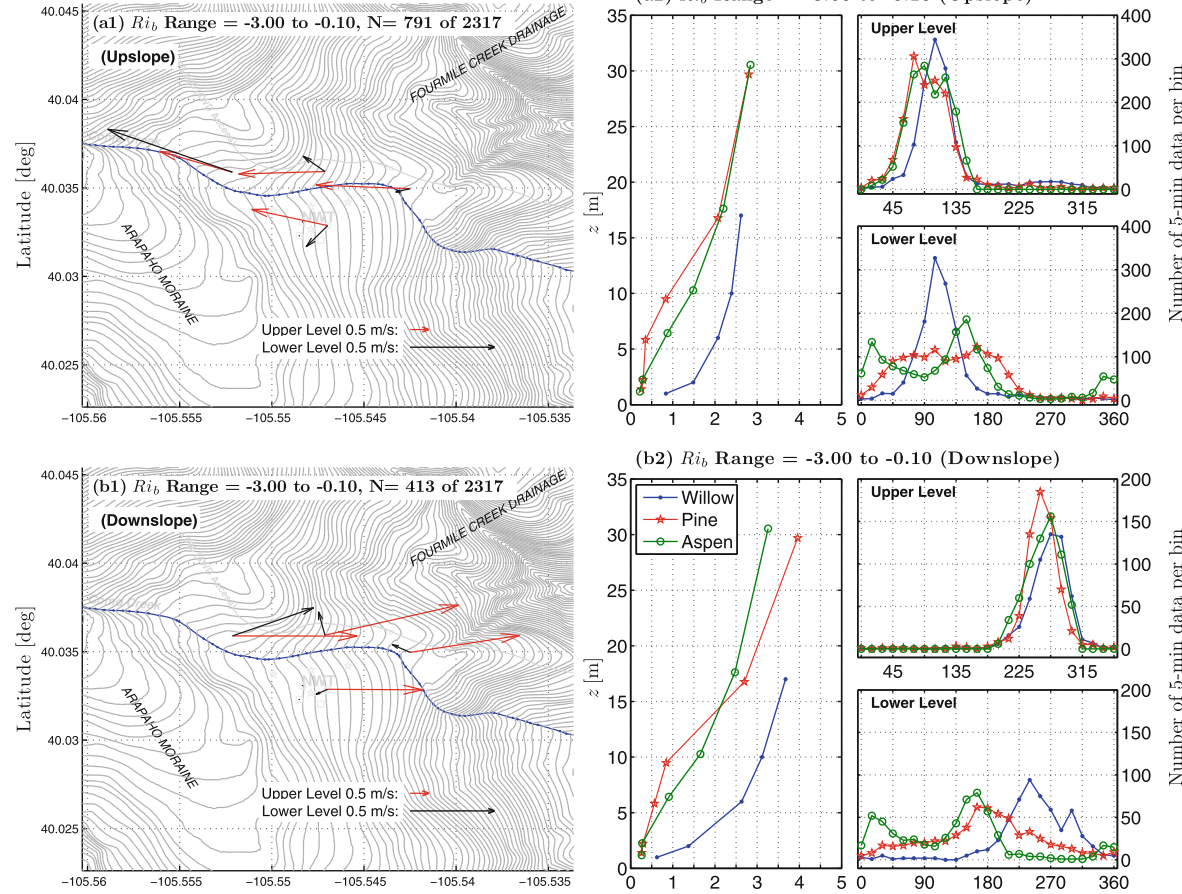

(b2) $R i_{b}$ Range $=-3.00$ to -0.10 (Downslope)
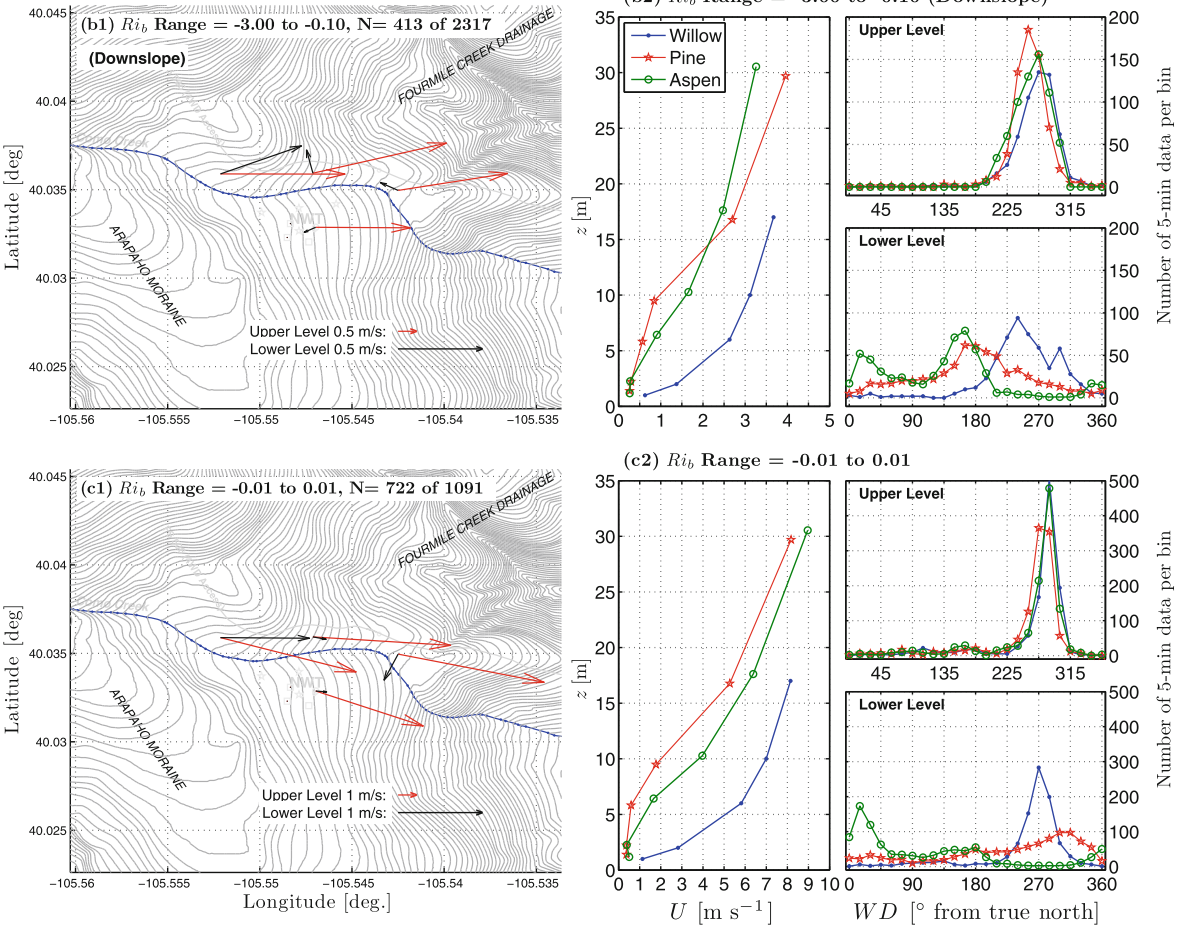

Fig. 8 (Left-hand column) Upper-level $(z>17 \mathrm{~m})$ and lower-level $(z<2.5 \mathrm{~m})$ wind vectors in the horizontal $(x-y)$ plane, and (right-hand column) corresponding wind speed $U$ profiles and wind direction $W D$ frequency distributions as the stability increases from (a)-(e). In (a1/a2) and (b1/b2) the data have been selected for upslope $\left(10^{\circ}<W D<150^{\circ}\right)$ and downslope $\left(200^{\circ}<W D<300^{\circ}\right)$ conditions based on $W D$ at the top of the Aspen tower. The $R i_{b}$ range and number of "good" data values $(N)$ along with the maximum possible number of data for this $R i_{b}$ bin are shown along with a reference scale for wind vectors. Note that the scale for $U$ is not the same in all panels

drainages (Fig. 8b2). For these conditions, local heating within the CSL generates a shallow upslope flow that is largely influenced by local topography, independent of the flow aloft, and restricted to areas with an overlying canopy (based on our limited number of tower locations). 

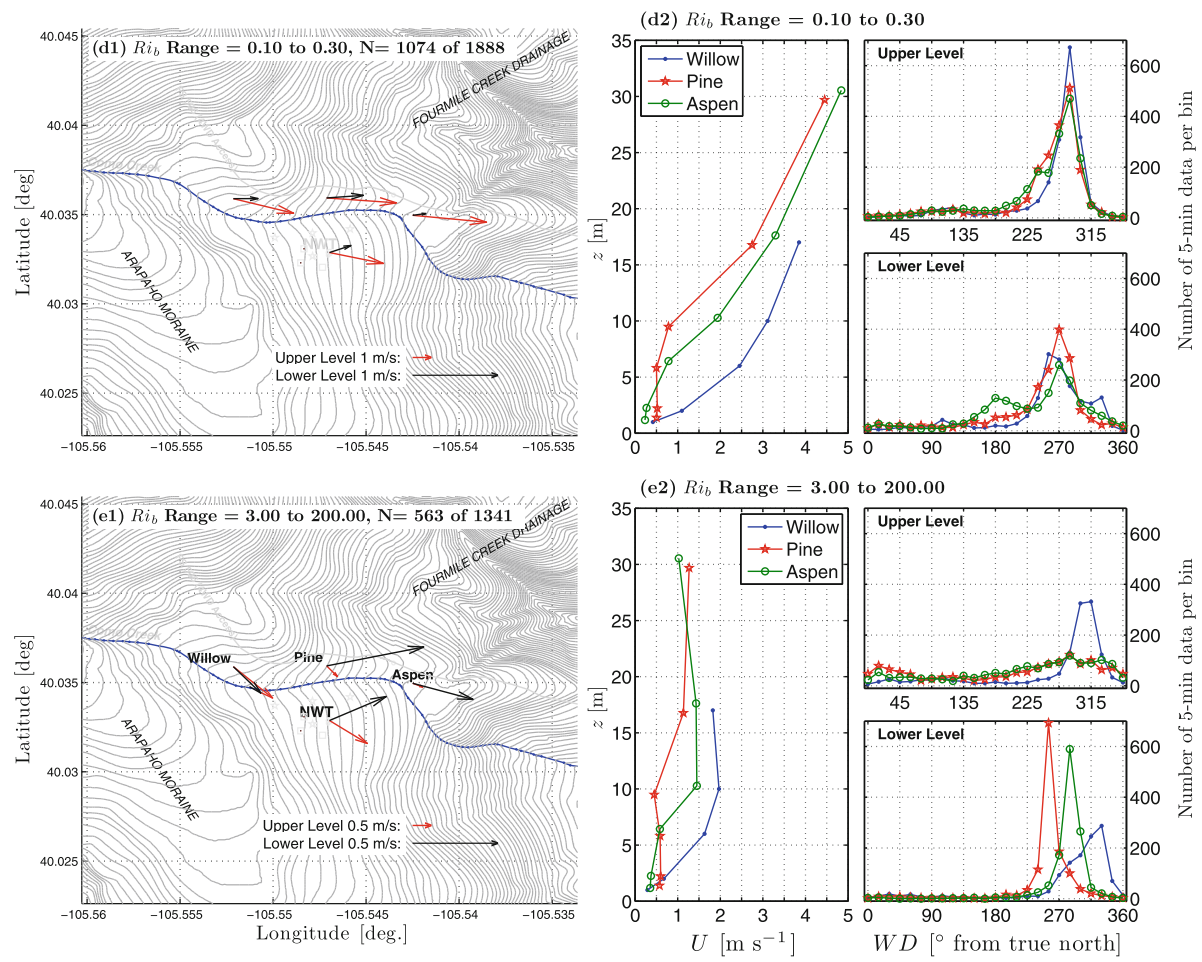

Fig. 8 continued

One of the intriguing aspects of the near-neutral flow at the Aspen site is that the CSL and above-canopy wind directions differed by up to $90^{\circ}$ (Fig. 9) and the CSL $\triangle W D$ SD-Bin becomes very large (Fig. 10). For near-neutral conditions, the upper- and lower-level winds at Willow, Pine, and NWT are all generally downslope (Fig. 8c1); CSL flow at Aspen, however, is upslope with a relatively wide $W D$ frequency distribution and a pronounced peak at $\approx 20^{\circ}$, which is from the direction of the Fourmile Creek drainage (Fig. 8c2). The reverse flow in the CSL at Aspen has many qualitative features (e.g., $w_{1}>0$ ), similar to what happens in the so-called "recirculation region" on the lee side of a shallow, simple hill in flume and wind-tunnel studies where separation occurs (Finnigan and Brunet 1995; Poggi and Katul 2007; Poggi et al. 2008), Those studies show that above-canopy flow decelerates above the recirculation region and the flow reversal is caused by an adverse streamwise pressure gradient $(\partial \bar{p} / \partial x)$ within the CSL. To understand this seemingly unlikely situation we note the following: (1) as air travels from Willow to Pine, $U$ decreases due to the dense canopy at Pine (e.g., in Fig. $8 \mathrm{c} 2$ at $z=17 \mathrm{~m}$ the decrease is $3 \mathrm{~m} \mathrm{~s}^{-1}$ ), (2) as air travels from Pine to Aspen, the flow accelerates by over $1 \mathrm{~m} \mathrm{~s}^{-1}$, due to the more open canopy at Aspen as well as the effect of the slope, and (3) $w_{1}$ in the CSL at Aspen is positive and at a maximum for near-neutral conditions (Fig. 7c). We also observe large (5-min) WD variations in the CSL_-indicating that the eddies penetrating into the canopy are intermittent and vigorous, and greatly affect the CSL flow-qualitatively similar to that found in the recirculation region in the laboratory (Poggi and Katul 2007). Though individual canopy elements can deflect the flow and explain the large $W D$ variability within the CSL, the fact that the most common $W D$ is coming upslope from the Fourmile creek drainage (Fig. 8c1) suggests that another 

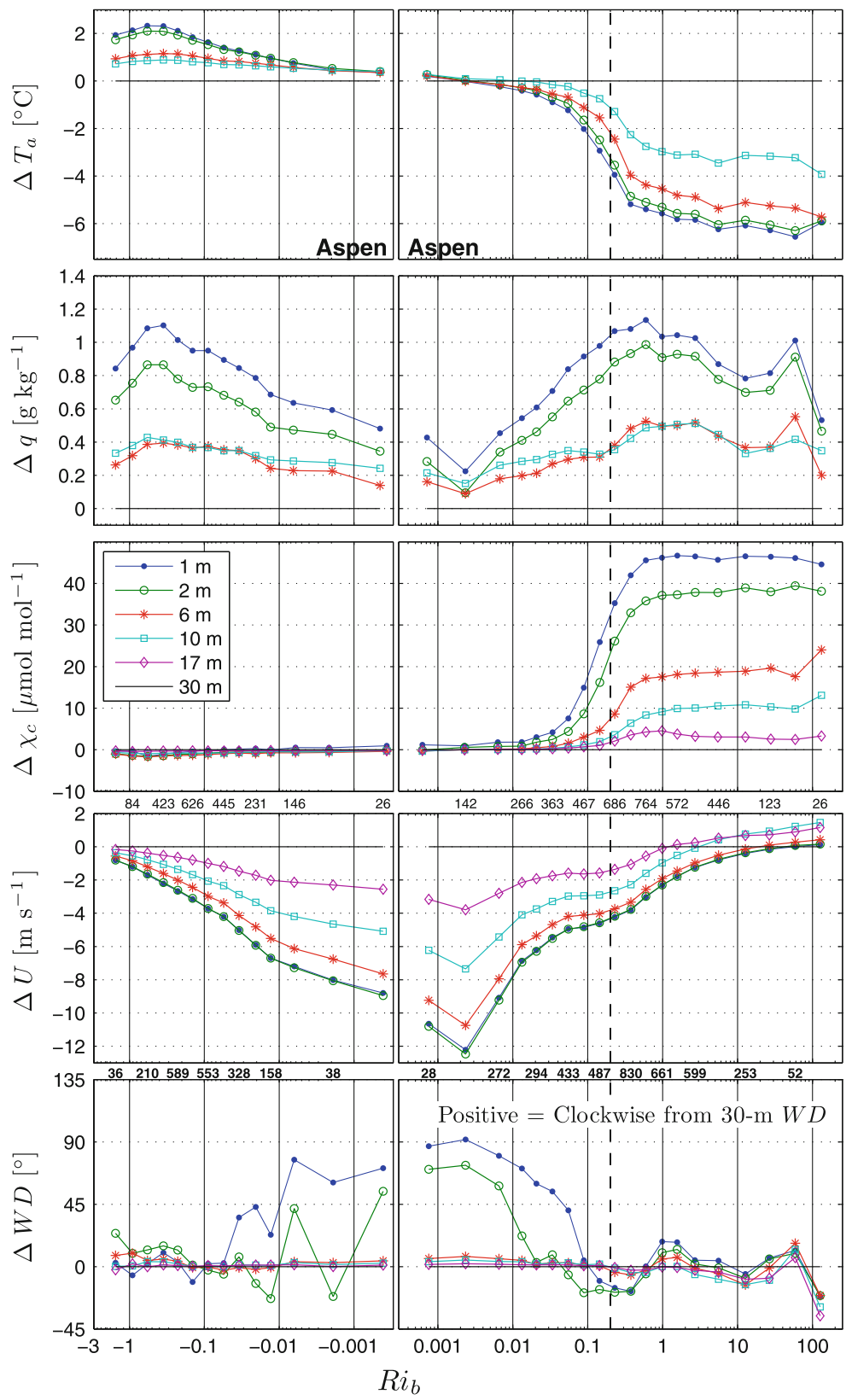

Fig. 9 Vertical differences relative to the 30-m level of: air temperature $T_{a}$, specific humidity $q, \mathrm{CO}_{2} \mathrm{~mole}$ fraction $\chi_{c}$, wind speed $U$, and wind direction $W D$ binned by the bulk Richardson number $R i_{b}$ at the Aspen tower. The legend with nominal sensor heights applies to all panels (see Tables 1 and 2 for exact sensor heights). The number of 5-min data within each bin are shown above/below the $\Delta U$ panel 

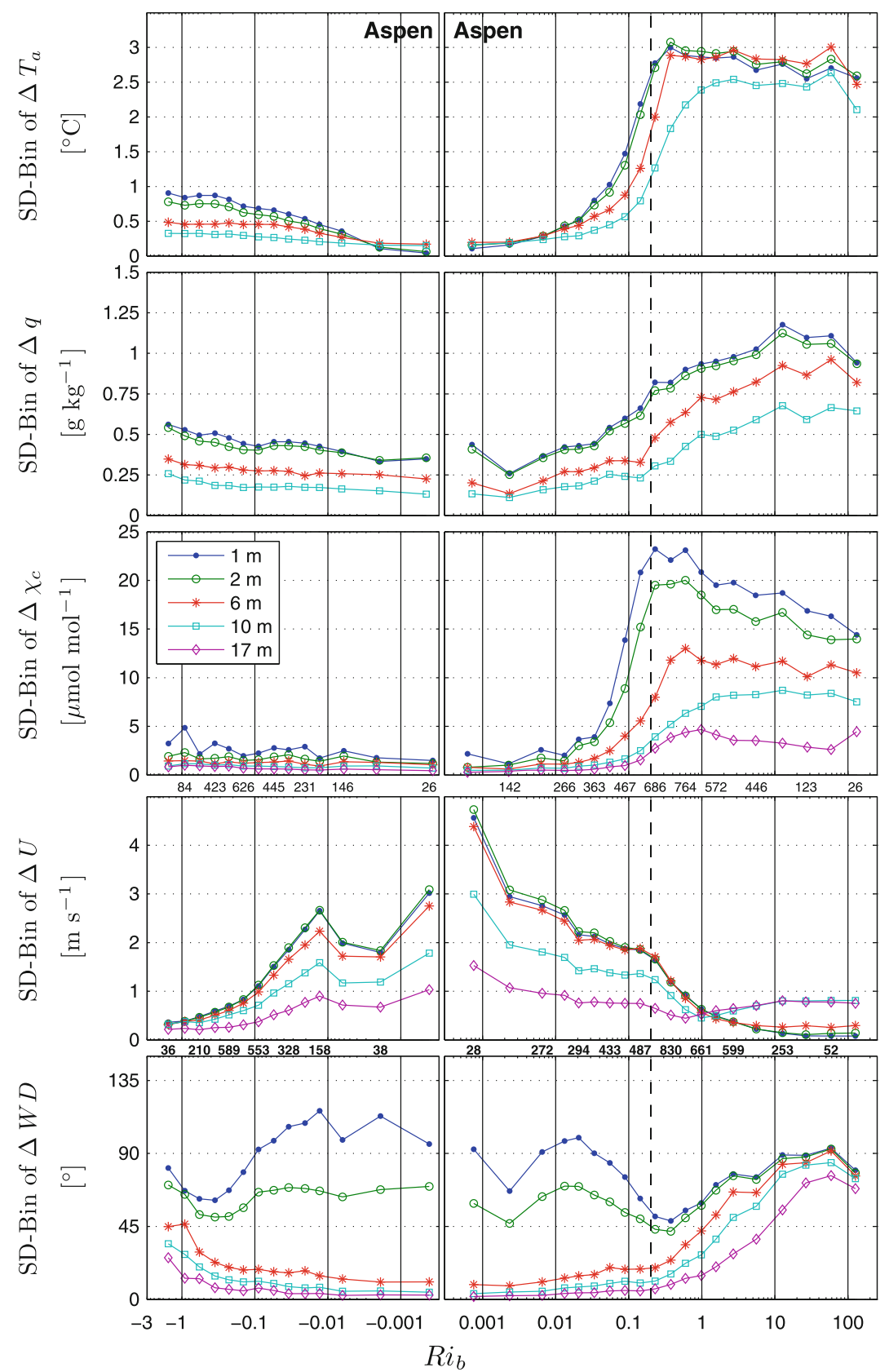

Fig. 10 As in Fig. 9, except the standard deviation (SD-Bin) of the data differences (relative to 30-m) within each $R i_{b}$ bin are shown

process is involved. We propose the following possible explanations: (1) the above-canopy flow decelerates and the CSL air adjusts to an adverse $\partial \bar{p} / \partial x$, or (2) the above-canopy flow accelerates and CSL air is entrained upwards into the above-canopy flow. This entrainment 
velocity is very small ( $w \approx 0.2 \mathrm{~m} \mathrm{~s}^{-1}$ as shown in Fig. 7 ), but, if true, continuity requires an induced horizontal flow within the CSL. The horizontal area over which these conditions might exist is unknown.

For moderately stable conditions, the upper- and lower-level flows are generally aligned and well-defined (Fig. 8d1-d2). For strongly stable conditions, upper-level wind motions are weak, the effect of buoyancy is strong, and the Willow and Aspen sites experience the "classic" jet-like elevated $U$ maximum characteristic of drainage flows (Fig. 8e2). At Pine, any jet-like $U$ maximum is less clear, perhaps due to sensor placement. As the air travels from Willow into the denser forest near Pine there is a $40 \%$ decrease in $U$ at $z \approx 17 \mathrm{~m}$. Between Pine and Aspen, a combination of the mean slope and the more open forest at Aspen, produces an acceleration in the flow and the $U$ maximum at Aspen becomes better-defined at $z \approx 10 \mathrm{~m}$ (just above canopy top). The above-canopy $U$ maximum at Aspen is most common in the early evening, but may be initiated at anytime during the night, and it often persisted for more than $3 \mathrm{~h}$ (results not shown). Also note that the 1-m winds are strongest at Pine, which has the steepest slope $\left(6.7^{\circ}\right)$ of all the sites. The upper-level winds appear to be influenced by the steep terrain in the upper left-hand corner of Fig. 8e1; however, because the upper levels are decoupled from the surface there is much WD variation aloft (Figs. 8e 2 and 10). In contrast, the low-level winds are best defined under strongly stable conditions and closely follow the local slope gradients.

\subsubsection{Unstable Conditions $\left(T_{a}, q, \chi_{c}\right)$}

Under strongly unstable conditions $\left(R i_{b}<-0.1\right)$, the gradients of $T_{a}$ and $q$ are, not surprisingly, both at a maximum and become smaller for near-neutral conditions (Fig. 9). After separating the upslope and downslope flows, one important observation is that the humidity of the upslope flow is significantly $(\approx 40 \%)$ greater than the downslope flow (Fig. 11). The large humidity dependence on the flow direction is most likely due to the source region of the air. Downslope air has either flowed over the Rocky Mountains or from a drier high-elevation location, whereas upslope air flows from the plains where the moisture content is greater. One surprise from Fig. 11 is that the upflowing air has lower $\chi_{c}$ than that of the downslope air. One might expect the upslope-moving air to be higher in $\mathrm{CO}_{2}$ due to the $\mathrm{CO}_{2}$ emissions of population centres in the lowlands; however, as the air travels upward from the plains any excess $\mathrm{CO}_{2}$ is absorbed by vegetation (during the growing season) and also convectively mixed into the boundary layer, bringing the above-canopy $\mathrm{CO}_{2}$ into close equilibrium with the overlying "background" atmospheric $\mathrm{CO}_{2}$.

For unstable conditions, the minimum in $\Delta \chi_{c}$ is near the height of maximum vegetation density due to the strongest photosynthetic uptake occurring at that level (Fig. 12). The difference between the $\mathrm{CO}_{2}$ aloft and the minimum $\mathrm{CO}_{2}$ is on the order of $2-3 \mu \mathrm{mol} \mathrm{mol}^{-1}$, which we call the "photosynthetic $\mathrm{CO}_{2}$ deficit". The $\mathrm{CO}_{2}$ deficit is greatest at the Willow site because it is dominated by low plants and shrubs with no overstorey shading the vegetation. However, because there is no canopy wind-sheltering at Willow, for near-neutral conditions its vertical $\mathrm{CO}_{2}$ profile is closer to being well-mixed than any of the other sites. The $\mathrm{CO}_{2}$ deficit depends on the canopy structure and has been reproduced in models (Siqueira and Katul 2010), but is not always observed in the field (e.g., Ohkubo et al. 2008). At the NWT tower, the $\mathrm{CO}_{2}$ deficit is similar to that observed in recent studies (Bowling et al. 2009).

For the dense-forest sites (USGS, Pine, NWT), soil respiration generates a 5-7 $\mu \mathrm{mol} \mathrm{mol}^{-1}$ surplus of near-ground $\mathrm{CO}_{2}$ that is not fully absorbed by the near-ground vegetation nor fully mixed into the atmosphere even under near-neutral conditions (Fig. 12). In contrast, at the more open (Aspen) and canopy-free (Willow) sites, the vertical mixing is more efficient and 
(a) Data from 1000 - 1600 MST (Upslope only)
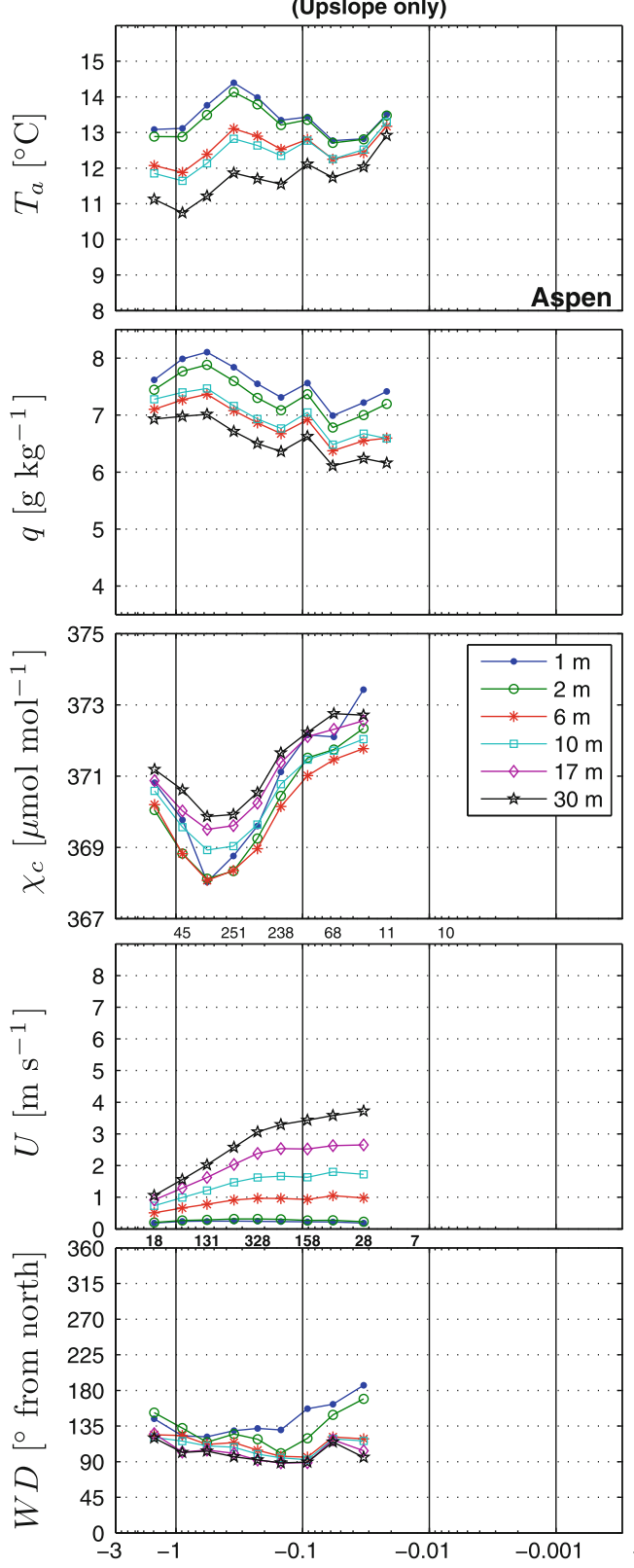

(b) Data from 1000 - 1600 MST (Downslope only)
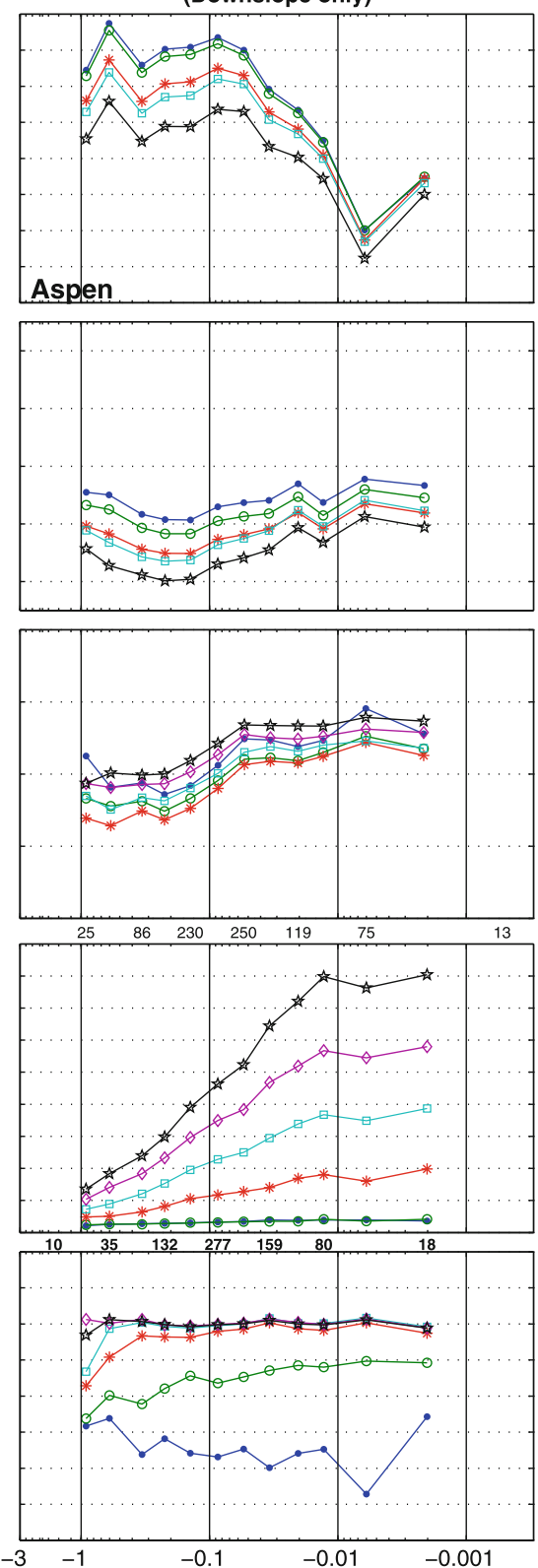

$R i_{b}$

Fig. 11 Daytime data at the Aspen tower separated into a upslope and $\mathbf{b}$ downslope conditions based on the wind direction at $30 \mathrm{~m}$. Bins containing less than 15 points are not shown

the ground cover and shrubs near the ground receive more solar radiation and thus absorb $\mathrm{CO}_{2}$ released from the soil. The canopy wind-sheltering effect has been discussed relative to CSL momentum transfer (e.g., Massman 1997) but the impact of sheltering also has 


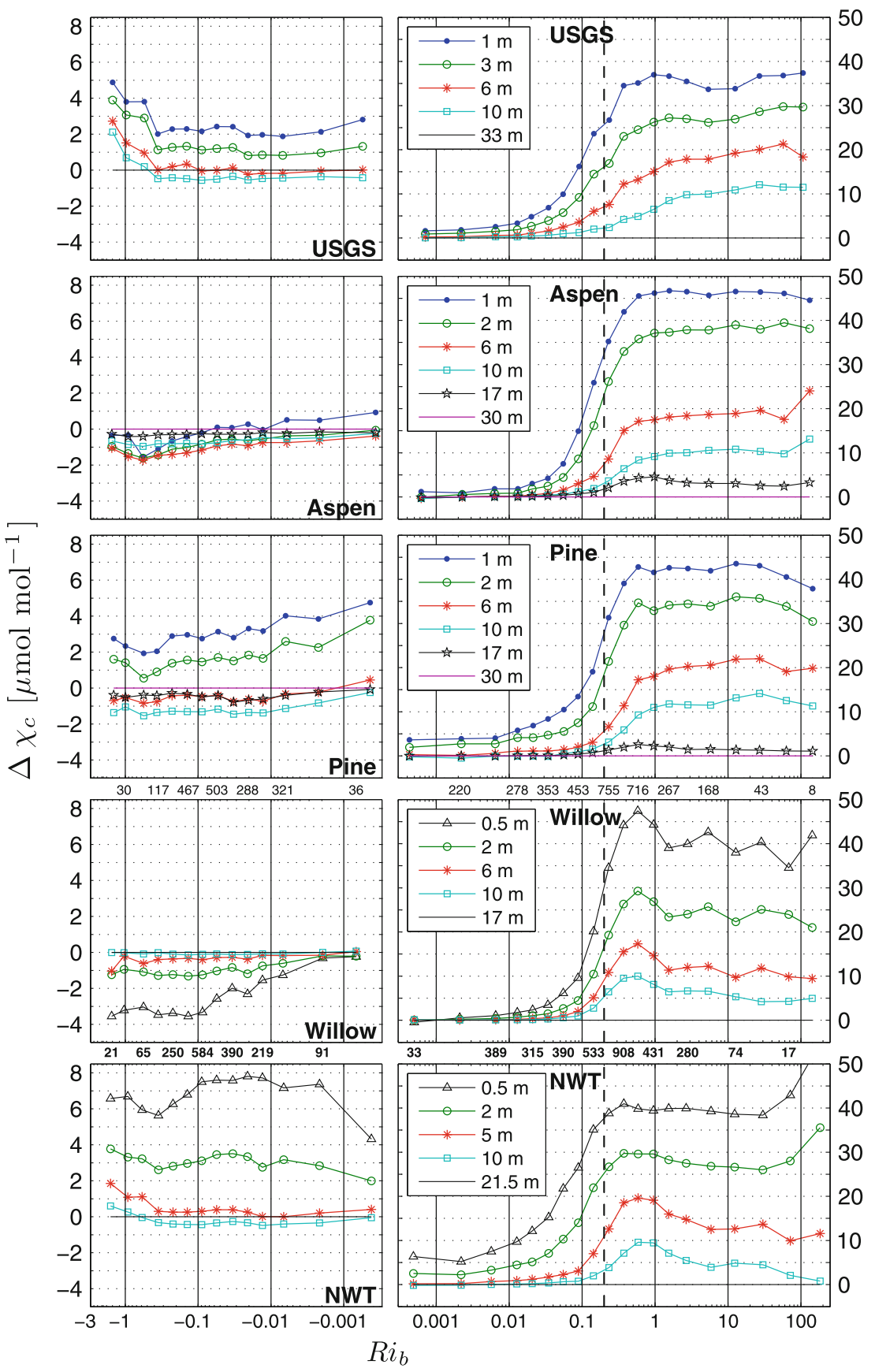

Fig. 12 The vertical differences of $\mathrm{CO}_{2}$ mole fraction $\chi_{c}$ measured at each tower binned by the bulk Richardson number (the highest $\chi_{c}$ measurement level is subtracted from the lower levels). Note that the $y$-axis range of the left and right panels differ. The number of 5-min data within each bin are shown above and below the Willow panel. The 1-m inlet from Willow has been excluded due to problems with this level 

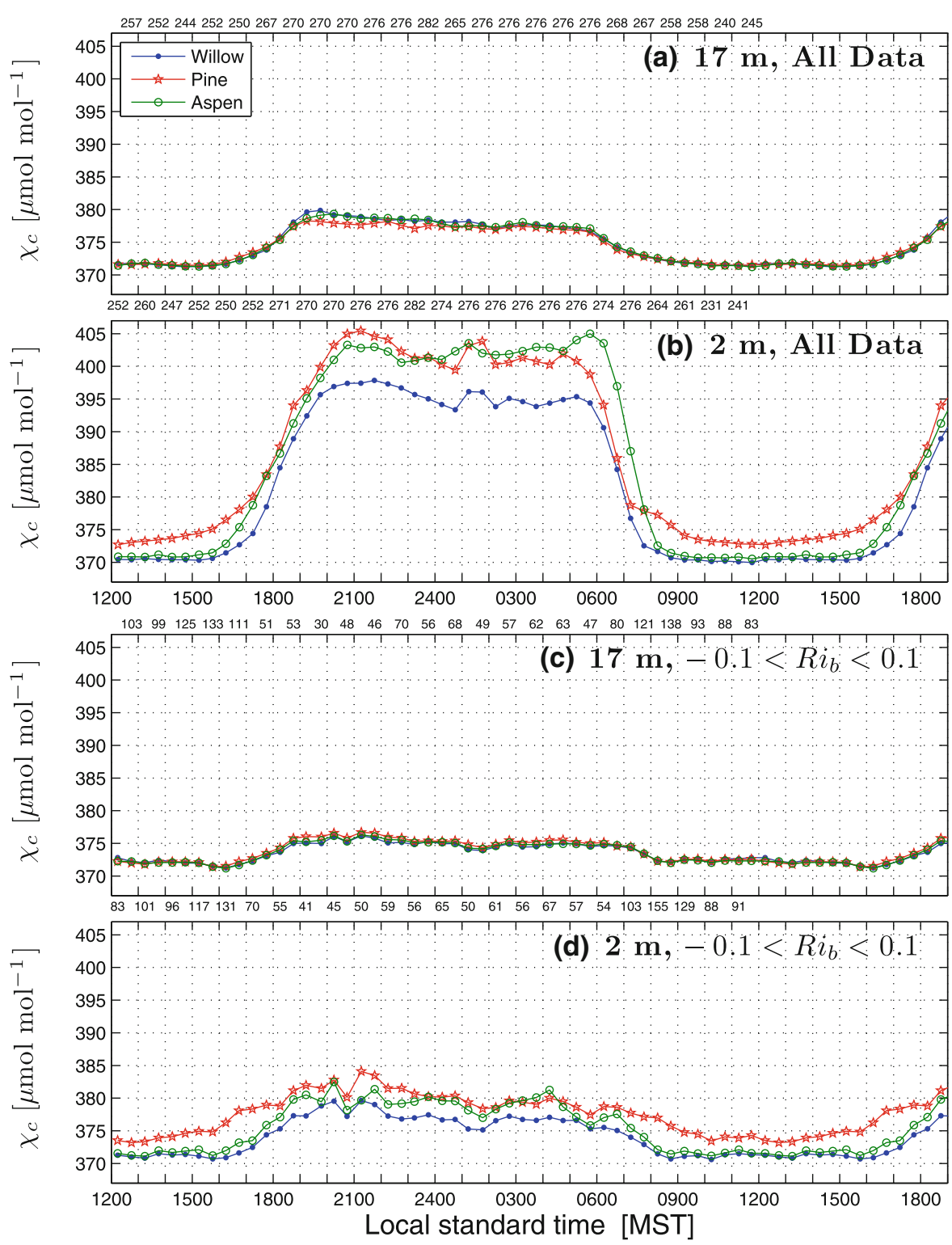

Fig. 13 Half-hourly binned $\mathrm{CO}_{2}$ mole fraction $\chi_{c}$ from the Willow, Pine, and Aspen towers at 2 and $17 \mathrm{~m}$ for $\mathbf{a}, \mathbf{b}$ all the data, and $\mathbf{c}, \mathbf{d}-0.1<R i_{b}<0.1$. The legend in $\mathbf{a}$ applies to all panels. The number of 5-min data values within each bin are shown above and below $\mathbf{a}$ and $\mathbf{c}$

significant implications when calculating a $\mathrm{CO}_{2}$ budget in a highly heterogenous landscape. For example, the horizontal $\mathrm{CO}_{2}$ differences at a given height can be influenced by the sheltering. To show this we plot the $\chi_{c}$ diurnal cycle at $2 \mathrm{~m}$ and $17 \mathrm{~m}$ for three of the towers for all conditions and for near-neutral conditions (Fig. 13). Observations from Fig. 13 are: (1) the $17-\mathrm{m} \chi_{c}$ differences are quite small $\left(<1 \mu \mathrm{mol} \mathrm{mol}^{-1}\right)$, (2) during the daytime the 2-m $\chi_{c}$ at Pine is $\approx 2 \mu \mathrm{mol} \mathrm{mol}^{-1}$ larger than at either Willow or Aspen, and this difference persists in near-neutral conditions, and (3) near the ground, the timing of $\mathrm{CO}_{2}$ changes during 
the morning and evening transitions differ by up to an hour among the sites. This timing difference is due to the canopy shading of the ground at Aspen, which delays the morning transition and results in an earlier evening transition to stable conditions. This effect can also be seen by comparing $R i_{b}$ at Willow and Aspen as shown in Fig. 3c.

\subsubsection{Stable Conditions $\left(T_{a}, q, \chi_{c}\right)$}

When conditions are stable and the shear generation of turbulence is relatively large (i.e., 0 $\left.<R i_{b}<0.05\right), T_{a}, q$, and $\chi_{c}$ profiles appear relatively well-mixed and the SD-Bins of the vertical differences are small (Figs. 9, 10). As stability increases, the scalar differences start to increase over a transitional regime between $0.05<R i_{b}<0.5$. For $R i_{b}>1$, the vertical differences become fairly constant and the SD-Bin is at a maximum (note that the SD-Bins of $\Delta T_{a}$ and $\Delta \chi_{c}$ are approximately $50 \%$ of the mean differences, while the SD-Bin of $\Delta q$ is the same order as the $\Delta q$ differences). The large SD-Bins for $R i_{b}>1$ are a result of the intermittent, episodic mixing that occurs under strongly stable conditions, as discussed in relation to the nighttime variability of $\sigma_{w}^{2}$ (Sect. 4.1). Because the mean scalar differences and SD-Bin are fairly constant for $R i_{b}>1$, we conclude that there is not a specific bulk-stability condition associated with these events (though they do appear at a certain time of the night as described in Sect. 4.1). Furthermore, the formation of the above-canopy $U$ maximum does not significantly alter the magnitude or frequency of the scalar-mixing events. The condition $R i_{b}>1$ also represents the regime where $(z-d) / \Lambda$ is fairly constant (e.g., Fig. 6), which implies that $(z-d) / \Lambda$ is a good indicator of the degree of scalar mixing (but not the abovecanopy $U$ maximum). There are a few exceptions to this. The SD-Bin of $\Delta \chi_{c}$ at $1 \mathrm{~m}$ and $2 \mathrm{~m}$ decreases from $20 \mu \mathrm{mol} \mathrm{mol}^{-1}$ to $15 \mu \mathrm{mol} \mathrm{mol}^{-1}$ as $R i_{b}$ increases from 1 to 100 , indicating that the mixing near the ground is somewhat less variable in strongly stable conditions. Also, $\Delta q$ differences become smaller as $R i_{b}$ increases from 1 to 100 . However, the SD-Bin of $\Delta q$ is the same order as the mean differences so the variability is large. We should also point out that the accuracy of the humidity measurements is on the order of $\pm 0.15 \mathrm{~g} \mathrm{~kg}^{-1}$, which contributes to the $\Delta q$ differences shown in Fig. 9.

Another factor that contributes to the different patterns in Fig. 9 is that $\mathrm{CO}_{2}$ is fairly uniform and has a long atmospheric lifetime above the RSL, but water vapour is much more short-lived and variable (e.g., the advection of different air masses has a "background" humidity that can vary significantly, whereas the "background" $\mathrm{CO}_{2}$ is relatively constant). What this means at the surface is that the $q$ flux is large relative to the mean humidity $q$, while the $\mathrm{CO}_{2}$ flux is small relative to mean $\chi_{c}$, and humidity $q$ at the upper levels is more affected by mesoscale variability.

\section{Conclusions}

We examined the late summer diurnal cycle of three scalar quantities $\left(T_{a}, q, \chi_{c}\right)$ and winds at a subalpine forest site near Niwot Ridge, Colorado. The instruments were mounted on five towers (up to $30 \mathrm{~m}$ tall) in a $1 \mathrm{~km}^{2}$ area with a $4-7^{\circ}$ topographic slope where the surface vegetation varied from treeless to dense coniferous forest. Katabatic flows are present over $90 \%$ of the time at night, while upslope and downslope flows are equally likely during the daytime. Maximum $q$ occurs throughout the canopy at the same time of day $(\approx 1730 \mathrm{MST})$ because $\sigma_{w}^{2}$ is at a minimum and transpiration, which distributes water vapour throughout the canopy layer, is active. In contrast to $q, \chi_{c}$ increases starting at the ground in the early evening (i.e., near the $\mathrm{CO}_{2}$ source) and then gradually increases 
at higher levels over several hours until all levels reach a quasi steady-state by about 2100 MST.

To study the effect of stability on scalar mixing and flow at the site we binned our measurements using a simple form of the bulk Richardson number $R i_{b}$ (based on 30-m wind speed and the potential temperature difference between $30 \mathrm{~m}$ and $1 \mathrm{~m}$ ). The $R i_{b}$ binning is a simple way to determine when the scalars are vertically well-mixed and can be used to determine conditions when the air near the ground is uncoupled from the higher level flow. This can be useful when trying to separate near-ground processes from those in the upper canopy (e.g., Schaeffer et al. 2008). Using this method we found distinct stability regimes that affect scalar mixing: a near-neutral well-mixed regime, a transitional regime between $0.05<R i_{b}<0.5$ where scalar differences begin to emerge and increase in magnitude, and a strongly-stable regime where consistent differences in scalars occur and are maintained (Figs. 9, 10). For unstable conditions $\left(R i_{b}<0\right)$, the mixing is complicated by the occurrence of both upslope and downslope flows (and photosynthesis/transpiration); by separating our data based on $W D$, we found upslope flows are weaker than downslope flows and have $\approx 60 \%$ higher specific humidity. We also found that the vegetative uptake of $\mathrm{CO}_{2}$ results in a $\mathrm{CO}_{2}$ deficit (relative to the above-canopy $\mathrm{CO}_{2}$ ) of $2-3 \mu \mathrm{mol} \mathrm{mol}^{-1}$ near the level of the maximum vegetation density. For the dense-canopy sites (LAI $\approx 4$ ), a wind-sheltering effect allows $\mathrm{CO}_{2}$ to increase near the ground. This result has implications for studies of $\mathrm{CO}_{2}$ advection over highly heterogeneous regions because these densecanopy locations can be "hotspots" of persistent and anomalously high $\mathrm{CO}_{2}$. One way to overcome this is to use long, perforated tubing to obtain a true average along the line (Leuning et al. 2008), but this is labour intensive and difficult to deploy over large areas. Simple models presented by Katul et al. (2006) have shown that changes in topography (with a uniform canopy) can have a significant impact on canopy-atmosphere $\mathrm{CO}_{2}$ exchange. Our result shows that CSL horizontal gradients are also affected by canopy sheltering in heterogeneous forests and implies that the vertical $\mathrm{CO}_{2}$ exchanges differ at each unique location.

Other than the canopy-sheltering effect, the scalars generally become well-mixed depending on the level of stability and turbulence; momentum transfer, however, is more complex. For our canopy-free site (Willow), the upper-level and near-ground winds are generally well-coupled. However, for sites with a canopy, the strong momentum absorption in the upper canopy allows the flow in the lower canopy to be modified in surprising ways. For our study site, the canopy winds are influenced by the two main creek drainages. These drainages become steeper $\approx 200 \mathrm{~m}$ to the east (downslope) of the eastern-most tower (Aspen). Under near-neutral conditions (i.e., strong above-canopy downslope winds), we found in-canopy upslope flows from the direction of one of the drainages. At the Aspen site, we also found the lower-canopy vertical wind is upward (away from the surface) indicating a separated flow. Under strongly unstable conditions with an upper-level (synoptic) downslope flow, we observed that air within the lower canopy moves upslope, and the wind direction within the canopy is strongly influenced by the two creek drainages. This decoupled, near-ground upslope flow only occurred at sites with a canopy. Under strongly stable conditions, a wind-speed maximum can form (i.e., the "nose" of the drainage flow) just above the canopy top. Under these conditions, the higher (30-m) level flow becomes decoupled, but the near-ground flow closely follows the local topographic slopes.

In order to better understand our observations, a model of the flow could provide valuable information, including the streamwise pressure gradient, but to create a successful model, detailed surface characteristics are needed. We recommend that quantifying the canopy 
structure and density around field sites (ideally, using lidar-based techniques) should be an integral part of measurement campaigns, as this can greatly improve the interpretation of tower-based wind measurements and provides essential information for modelling the flow.

Acknowledgements Tony Delany created TGaMS and oversaw its operation during CME04. Andy Watt helped construct, deploy and maintain the AIRCOA systems. Steve Semmer, Gordon Maclean, Kurt Knudsen, Chris Golubieski, and many others at NCAR/ISFF deployed, instrumented, and dismantled the EOL Towers. We thank Dave Bowling for constructive comments on an early version of the manuscript. We also thank two anonymous reviewers for their insightful comments. The NWT tower is supported by a grant from the South Central Section of the National Institute for Global Environmental Change (NIGEC) through the US Department of Energy (BER Program, Cooperative Agreement No. DE-FC03-90ER61010). CME04 was supported by the NCAR Director Opportunity Fund and NSF grant EAR-0321918. The National Center for Atmospheric Research (NCAR) is sponsored by the National Science Foundation.

\section{References}

Acevedo OC, da Silva R, Fitzjarrald DR, Moraes OLL, Sakai RK, Czikowsky MJ (2008) Nocturnal vertical $\mathrm{CO}_{2}$ accumulation in two Amazonian ecosystems. J Geophys Res 113:G00B04. doi:10.1029/ 2007JG000612

Aubinet $\mathrm{M}$ (2008) Eddy covariance $\mathrm{CO}_{2}$ flux measurements in nocturnal conditions: an analysis of the problem. Ecol Appl 18:1368-1378

Aubinet M, Heinesch B, Yernaux M (2003) Horizontal and vertical $\mathrm{CO}_{2}$ advection in a sloping forest. Boundary-Layer Meteorol 108:397-417

Bakwin PS, Tans PP, Zhao C, Ussler W, Quesnell E (1995) Measurements of carbon-dioxide on a very tall tower. Tellus 47:535-549

Baldocchi DD, Hicks BB, Meyers TP (1988) Measuring biosphere-atmosphere exchanges of biologically related gases with micrometeorological methods. Ecology 69(5):1331-1340

Banta RM, Darby LS, Fast JD, Pinto JO, Whiteman CD, Shaw WJ, Orr BW (2004) Nocturnal low-level jet in a mountain basin complex. Part I: evolution and effects on local flows. J Appl Meteorol 43:1348-1365

Barry RG (2008) Mountain weather and climate, 3rd edn. Cambridge University Press, Cambridge, UK, 512 pp

Belcher SE, Finnigan JJ, Harman IN (2008) Flows through forest canopies in complex terrain. Ecol Appl 18:1436-1453

Bonan GB (2008) Forests and climate change: forcings, feedbacks, and the climate benefits of forests. Science 320:1444-1449

Bowling DR, Miller JB, Rhodes ME, Burns SP, Monson RK, Baer D (2009) Soil, plant, and transport influences on methane in a subalpine forest under high ultraviolet irradiance. Biogeoscience 6(7):1311-1324

Brazel AJ, Brazel SW (1983) Summer diurnal wind patterns at 3,000 m surface level, Front Range, Colorado, USA. Phys Geogr 4:53-61

Brunet Y, Finnigan JJ, Raupach MR (1994) A wind tunnel study of air flow in waving wheat: single point velocity measurements. Boundary-Layer Meteorol 70:95-132

Burns SP, Delany AC, Sun J, Stephens B, Oncley S, Maclean GD, Semmer SR, Schröter J, Ruppert J (2009) An evaluation of calibration techniques for in situ carbon dioxide measurements using a programmable portable trace-gas measuring system. J Atmos Ocean Technol 26:291-316. doi:10.1175/ 2008JTECHA1080.1

Businger JA (1973) Turbulent transfer in the atmospheric surface layer. In: Haugen DA (ed) Workshop on micrometeorology, Amer Meteorol Soc, Boston, pp 67-100

Fedorovich E, Shapiro A (2009) Structure of numerically simulated katabatic and anabatic flows along steep slopes. Acta Geophys 57:981-1010

Feigenwinter C, Bernhofer C, Eichelmann U, Heinesch B, Hertel M, Janous D, Kolle O, Lagergren F, Lindroth A, Minerbi S, Moderow U, Molder M, Montagnani L, Queck R, Rebmann C, Vestin P, Yernaux M, Zeri M, Ziegler W, Aubinet M (2008) Comparison of horizontal and vertical advective $\mathrm{CO}_{2}$ fluxes at three forest sites. Agric For Meteorol 148:12-24

Feigenwinter C, Montagnani L, Aubinet M (2010) Plot-scale vertical and horizontal transport of $\mathrm{CO}_{2}$ modified by a persistent slope wind system in and above an alpine forest. Agric For Meteorol 150:665-673. doi:10.1016/j.agrformet.2009.05.009

Finnigan JJ (2000) Turbulence in plant canopies. Annu Rev Fluid Mech 32:519-571 
Finnigan JJ (2004) A re-evaluation of long-term flux measurement techniques. Part II: coordinate systems. Boundary-Layer Meteorol 113:1-41

Finnigan J (2008) An introduction to flux measurements in difficult conditions. Ecol Appl 18:1340-1350

Finnigan JJ, Belcher SE (2004) Flow over a hill covered with a plant canopy. Q J Roy Meteorol Soc 130:1-29

Finnigan JJ, Brunet Y (1995) Turbulent airflow in forests on flat and hilly terrain. In: Coutts MP, Grace J (eds) Wind and trees. Cambridge University Press, Cambridge, pp 3-40

Finnigan JJ, Clement R, Malhi Y, Leuning R, Cleugh HA (2003) A re-evaluation of long-term flux measurement techniques. Part I: averaging and coordinate rotation. Boundary-Layer Meteorol 107:1-48

Froelich NJ, Schmid HP (2006) Flow divergence and density flows above and below a deciduous forest. Part II: below-canopy thermotopographic flows. Agric For Meteorol 138:29-43

Galperin B, Sukoriansky S, Anderson PS (2007) On the critical Richardson number in stably stratified turbulence. Atmos Sci Let 8:65-69

Harman IN, Finnigan JJ (2007) A simple unified theory for flow in the canopy and roughness sublayer. Boundary-Layer Meteorol 123:339-363

Harman IN, Finnigan JJ (2008) Scalar concentration profiles in the canopy and roughness sublayer. Boundary-Layer Meteorol 129:323-351

Hirano T, Kim H, Tanaka Y (2003) Long-term half-hourly measurement of soil $\mathrm{CO}_{2}$ concentration and soil respiration in a temperate deciduous forest. J Geophys Res 108(D20):4631. doi:10.1029/2003JD003766

Horst TW, Doran JC (1986) Nocturnal drainage flow on simple slopes. Boundary-Layer Meteorol 34:263-286

Inoue E (1963) On the turbulent structure of airflow within crop canopies. J Meteorol Soc Jpn 41:317-326

Kaimal JC, Finnigan JJ (1994) Atmospheric boundary layer flows: their structure and measurement. Oxford University Press, New York, 289 pp.

Katul GG, Finnigan JJ, Poggi D, Leuning R, Belcher SE (2006) The influence of hilly terrain on canopyatmosphere carbon dioxide exchange. Boundary-Layer Meteorol 118:189-216

Komatsu H, Hotta N, Kuraji K, Suzuki M, Oki T (2005) Classification of vertical wind speed profiles observed above a sloping forest at nighttime using the bulk Richardson number. Boundary-Layer Meteorol 115:205-221

Komatsu H, Hotta N, Kuraji K, Suzuki M (2008) Relationship between nighttime wind speeds and thermal conditions above a sloping forest. J Meteorol Soc Jpn 86:805-815

Kossmann M, Fiedler F (2000) Diurnal momentum budget analysis of thermally induced slope winds. Meteorol Atmos Phys 75:195-215

Lee X (2000) Air motion within and above forest vegetation in non-ideal conditions. For Ecol Manag 135:3-18

Leuning R, Zegelin SJ, Jones K, Keith H, Hughes D (2008) Measurement of horizontal and vertical advection of $\mathrm{CO}_{2}$ within a forest canopy. Agric For Meteorol 148:1777-1797

Mahrt L (1982) Momentum balance of gravity flows. J Atmos Sci 39:2701-2711

Mahrt L (1999) Stratified atmospheric boundary layers. Boundary-Layer Meteorol 90:375-396

Mahrt L (2010) Computing turbulent fluxes near the surface: needed improvements. Agric For Meteorol 150:501-509

Massman WJ (1997) An analytical one-dimensional model of momentum transfer by vegetation of arbitrary structure. Boundary-Layer Meteorol 83:407-421

Mauritsen T, Svensson G (2007) Observations of stably stratified shear-driven atmospheric turbulence at low and high Richardson numbers. J Atmos Sci 64:645-655

Monson RK, Turnipseed AA, Sparks JP, Harley PC, Scott-Denton LE, Sparks K, Huxman TE (2002) Carbon sequestration in a high-elevation, subalpine forest. Glob Change Biol 8:459-478

Monson RK, Prater MR, Hu J, Burns SP, Sparks JP, Sparks KL, Scott-Denton LE (2010) Tree species effects on ecosystem water-use efficiency in a high-elevation, subalpine forest. Oecologia 162(2):491-504. doi:10.1007/s00442-009-1465-z

Monti P, Fernando HJS, Princevac M, Chan WC, Kowalewski TA, Pardyjak ER (2002) Observations of flow and turbulence in the nocturnal boundary layer over a slope. J Atmos Sci 59:2513-2534

Moore DJP, Hu J, Sacks WJ, Schimel DS, Monson RK (2008) Estimating transpiration and the sensitivity of carbon uptake to water availability in a subalpine forest using a simple ecosystem process model informed by measured net $\mathrm{CO}_{2}$ and $\mathrm{H}_{2} \mathrm{O}$ fluxes. Agric For Meteorol 148:1467-1477

Nakamura R, Mahrt L (2001) Similarity theory for local and spatially averaged momentum fluxes. Agric For Meteorol 108:265-279

Nieuwstadt FTM (1984) The turbulent structure of the stable, nocturnal boundary-layer. J Atmos Sci 41:22022216

Ohkubo S, Kosugi Y, Takanashi S, Matsuo N, Tani M, Nik AR (2008) Vertical profiles and storage fluxes of $\mathrm{CO}_{2}$, heat and water in a tropical rainforest at Pasoh, Peninsular Malaysia. Tellus 60:569-582

Oncley SP (2004) CME04 report. NCAR Earth Observing Laboratory (EOL) Integrated Surface Flux Facility (ISFF). http://www.eol.ucar.edu/cme04/ 
Oncley SP, Schwenz K, Burns SP, Sun J, Monson RK (2009) A cable-borne tram for atmospheric measurements along transects. J Atmos Ocean Technol 26(3):462-473. doi:10.1175/2008JTECHA1158.1

Patton EG, Katul GG (2009) Turbulent pressure and velocity perturbations induced by gentle hills covered with sparse and dense canopies. Boundary-Layer Meteorol 133:189-217

Pérez I, Sánchez M, García M, de Torre B (2009) Daily and annual cycle of $\mathrm{CO}_{2}$ concentration near the surface depending on boundary layer structure at a rural site in Spain. Theor Appl Climatol 98:269-277. doi:10. 1007/s00704-009-0112-2

Physick WL, Garratt JR (1995) Incorporation of a high-roughness lower boundary into a mesoscale model for studies of dry deposition over complex terrain. Boundary-Layer Meteorol 74:55-71

Poggi D, Katul GG (2007) Turbulent flows on forested hilly terrain: the recirculation region. Q J Roy Meteorol Soc 133:1027-1039

Poggi D, Katul GG, Albertson JD (2004a) A note on the contribution of dispersive fluxes to momentum transfer within canopies-research note. Boundary-Layer Meteorol 111:615-621

Poggi D, Porporato A, Ridolfi L, Albertson JD, Katul GG (2004b) The effect of vegetation density on canopy sub-layer turbulence. Boundary-Layer Meteorol 111:565-587

Poggi D, Katul GG, Finnigan JJ, Belcher SE (2008) Analytical models for the mean flow inside dense canopies on gentle hilly terrain. Q J Roy Meteorol Soc 134:1095-1112

Poulos GS, Burns SP (2003) An evaluation of bulk Ri-based surface layer flux formulas for stable and very stable conditions with intermittent turbulence. J Atmos Sci 60:2523-2537. doi:10.1175/ 1520-0469(2003)060<2523:AEOBRS > 2.0.CO;2

Raupach MR (1987) A Lagrangian analysis of scalar transfer in vegetation canopies. Q J Roy Meteorol Soc 113:107-120

Raupach MR, Thom AS (1981) Turbulence in and above plant canopies. Annu Rev Fluid Mech 13:97-129

Raupach MR, Finnigan JJ, Brunet Y (1996) Coherent eddies and turbulence in vegetation canopies: the mixing-layer analogy. Boundary-Layer Meteorol 78:351-382

Richardson LF (1925) Turbulence and vertical temperature differences near trees. Philos Mag 49:81-90

Ryan MG, Law B (2005) Interpreting, measuring, and modeling soil respiration. Biogeochemistry 73:3-27

Schaeffer SM, Anderson DE, Burns SP, Monson RK, Sun J, Bowling DR (2008) Canopy structure and atmospheric flows in relation to the $\delta^{13} \mathrm{C}$ of respired $\mathrm{CO}_{2}$ in a subalpine coniferous forest. Agric For Meteorol 148:592-605. doi:10.1016/j.agrformet.2007.11.003

Scott-Denton LE, Sparks KL, Monson RK (2003) Spatial and temporal controls of soil respiration rate in a high-elevation, subalpine forest. Soil Biol Biochem 35:525-534

Sedlak P, Aubinet M, Heinesch B, Janous D, Pavelka M, Potuznikova K, Yernaux M (2010) Night-time airflow in a forest canopy near a mountain crest. Agric For Meteorol 150:736-744

Siqueira MB, Katul GG (2010) An analytical model for the distribution of $\mathrm{CO}_{2}$ sources and sinks, fluxes, and mean concentration within the roughness sub-layer. Boundary-Layer Meteorol 135:31-50. doi:10.1007/ s10546-009-9453-8

Smith RB (1979) The influence of mountains on the atmosphere. Adv Geophys 21:87-230

Staebler RM, Fitzjarrald DR (2004) Observing subcanopy $\mathrm{CO}_{2}$ advection. Agric For Meteorol 122:139-156. doi:10.1016/j.agrformet.2003.09.011

Staebler RM, Fitzjarrald DR (2005) Measuring canopy structure and the kinematics of subcanopy flows in two forests. J Appl Meteorol 44:1161-1179

Stephens BB, Watt A, Maclean G (2006) An autonomous inexpensive robust $\mathrm{CO}_{2}$ analyzer (AIRCOA). In: Miller J (ed) 13th WMO/IAEA meeting of experts on carbon dioxide concentration and related tracers measurement techniques. World Meteorological Organization, Global Atmosphere Watch Programme, Geneva, Switzerland, WMO tech. doc. no. 1359; GAW report no. 168, pp 95-99. http://www.wmo.int/ pages/prog/arep/gaw/documents/gaw168.pdf

Su HB, Schmid H, Vogel C, Curtis P (2008) Effects of canopy morphology and thermal stability on mean flow and turbulence statistics observed inside a mixed hardwood forest. Agric For Meteorol 148:862-882. doi:10.1016/j.agrformet.2007.12.002

Sun J (2007) Tilt corrections over complex terrain and their implication for $\mathrm{CO}_{2}$ transport. Boundary-Layer Meteorol 124:143-159

Sun J, Burns SP, Delany AC, Oncley SP, Turnipseed AA, Stephens BB, Lenschow DH, LeMone MA, Monson RK, Anderson DE (2007) $\mathrm{CO}_{2}$ transport over complex terrain. Agric For Meteorol 145:1-21. doi:10. 1016/j.agrformet.2007.02.007

Sun J, Oncley SP, Burns SP, Stephens BB, Lenschow DH, Campos T, Monson RK, Schimel DS, Sacks WJ, De Wekker SFJ, Lai CT, Lamb B, Ojima D, Ellsworth PZ, Sternberg LSL, Zhong S, Clements C, Moore DJP, Anderson DE, Watt AS, Hu J, Tschudi M, Aulenbach S, Allwine E, Coons T (2010) A multiscale and multidisciplinary investigation of ecosystem-atmosphere $\mathrm{CO}_{2}$ exchange over the Rocky Mountains of Colorado. Bull Am Meteorol Soc 91(2):209-230. doi:10.1175/2009BAMS2733.1 
Sutton OG (1953) Micrometeorology : a study of physical processes in the lowest layers of the Earth's atmosphere. McGraw-Hill, New York, 333 pp

Turnipseed AA, Blanken PD, Anderson DE, Monson RK (2002) Energy budget above a high-elevation subalpine forest in complex topography. Agric For Meteorol 110:177-201

Turnipseed AA, Anderson DE, Blanken PD, Baugh WM, Monson RK (2003) Airflows and turbulent flux measurements in mountainous terrain. Part 1: canopy and local effects. Agric For Meteorol 119: $1-21$

Turnipseed AA, Anderson DE, Burns S, Blanken PD, Monson RK (2004) Airflows and turbulent flux measurements in mountainous terrain. Part 2: mesoscale effects. Agric For Meteorol 125: 187-205

Vickers D, Mahrt L (2006) A solution for flux contamination by mesoscale motions with very weak turbulence. Boundary-Layer Meteorol 118:431-447

Whiteman CD (2000) Mountain meteorology: fundamentals and applications. Oxford University Press, New York, $355 \mathrm{pp}$

Whiteman CD, Zhong SY (2008) Downslope flows on a low-angle slope and their interactions with valley inversions. Part I: observations. J Appl Meteorol Clim 47:2023-2038

Wilczak JM, Oncley SP, Stage SA (2001) Sonic anemometer tilt correction algorithms. Boundary-Layer Meteorol 99:127-150

Yi C (2008) Momentum transfer within canopies. J Appl Meteorol Clim 47:262-275

Yi C, Davis KJ, Berger BW, Bakwin PS (2001) Long-term observations of the dynamics of the continental planetary boundary layer. J Atmos Sci 58:1288-1299

Yi C, Monson RK, Zhai ZQ, Anderson DE, Lamb B, Allwine G, Turnipseed AA, Burns SP (2005) Modeling and measuring the nocturnal drainage flow in a high-elevation, subalpine forest with complex terrain. J Geophys Res 110:D22,303. doi:10.1029/2005JD006282

Yi C, Anderson DE, Turnipseed AA, Burns SP, Sparks JP, Stannard DI, Monson RK (2008) The contribution of advective fluxes to net ecosystem exchange in a high-elevation, subalpine forest. Ecol Appl 18:1379-1390. doi:10.1890/06-0908.1

Zilitinkevich SS, Elperin T, Kleeorin N, Rogachevskii I (2007) Energy- and flux-budget (EFB) turbulence closure model for stably stratified flows. Part I: steady-state, homogeneous regimes. Boundary-Layer Meteorol 125:167-191 